Article

\title{
Phytic Acid Doped Polyaniline as a Binding Coating Promoting Growth of Prussian Blue on Cotton Fibers for Adsorption of Copper Ions
}

\author{
Xueyao Wang, Qiang Li, Dongmei Yang, Xianhui An and Xueren Qian *
}

Citation: Wang, X.; Li, Q.; Yang, D.; An, X.; Qian, X. Phytic Acid Doped Polyaniline as a Binding Coating Promoting Growth of Prussian Blue on Cotton Fibers for Adsorption of Copper Ions. Coatings 2022, 12, 138 https://doi.org/10.3390/ coatings 12020138

Academic Editor: Joseph L. Keddie

Received: 19 December 2021

Accepted: 21 January 2022

Published: 25 January 2022

Publisher's Note: MDPI stays neutral with regard to jurisdictional claims in published maps and institutional affiliations.

Copyright: (C) 2022 by the authors. Licensee MDPI, Basel, Switzerland. This article is an open access article distributed under the terms and conditions of the Creative Commons Attribution (CC BY) license (https:// creativecommons.org/licenses/by/ $4.0 /)$.
Key Laboratory of Bio-Based Material Science and Technology, Ministry of Education, Northeast Forestry University, Harbin 150040, China; 873574352@nefu.edu.cn (X.W.); 2020115563@nefu.edu.cn (Q.L.); yyddmm1980122@163.com (D.Y.); anxianh509@163.com (X.A.)

* Correspondence: qianxueren@nefu.edu.cn; Tel.: +86-133-0464-2918
Abstract: In recent years, the elimination of heavy metals from wastewater has become an important topic due to rapid industrialization, and it is of considerable interest to develop renewable and degradable materials for this purpose. In this work, a novel Prussian blue/polyaniline@cotton fibers (PB/PANI@CFs) composite was fabricated by a two-step process. Phytic acid doped PANI as a binding coating greatly promoted both the growth of $\mathrm{PB}$ and the adsorption of $\mathrm{Cu}^{2+}$. The deposition ratio of $\mathrm{PB}$ was as high as $24.68 \%$. Scanning electron microscopy (SEM) displayed that PB nanoparticles were grown more uniformly in the composite and formed a perfect nanocube structure compared with PB@CFs. The successful deposition of both PB and PANI on CFs was demonstrated by X-ray diffraction (XRD), Fourier transform infrared spectroscopy (FITR), and X-ray photoelectron spectroscopy (XPS). The effect of adsorption time, adsorbent dose, initial $\mathrm{pH}$ value, and initial copper sulphate concentration on the adsorption of PB/PANI@CFs composite for $\mathrm{Cu}^{2+}$ was studied by static adsorption and was compared with those of PANI@CFs and PB@CFs. The results showed that the maximum removal efficiency of $\mathrm{Cu}^{2+}$ by PB/PANI@CFs can reach $93.4 \%$ within $5 \mathrm{~h}$, and the maximum adsorption capacity of $\mathrm{Cu}^{2+}$ can reach $31.93 \mathrm{mg} \cdot \mathrm{g}^{-1}$. The adsorption of $\mathrm{Cu}^{2+}$ on PB/PANI@CFs followed the pseudo-second order kinetic model and conformed to the Freundlich adsorption isothermal model. The PB-functionalized CFs provided new insights into the design of efficient and low-cost absorbents for heavy metal remediation. The proposed process solves two problems simultaneously, i.e., the utilization of environmentally friendly and biodegradable biomass resources and the adsorption of heavy metal ions, and is a good approach to achieve high-quality and sustainable development.

Keywords: cotton fibers; Prussian blue; polyaniline; phytic acid; binding coating; copper ion adsorption

\section{Introduction}

Water is an important resource to human life. However, with the development of society, more and more factors seriously affect the water environment, which threatens human health and restricts the development of economy and society [1]. Therefore, researchers have begun to focus on the treatment of wastewater [2]. The heavy metal contamination has become a prominent environmental issue worldwide in recent years. Heavy metals such as copper $\left(\mathrm{Cu}^{2+}\right)$ are among the most common contaminants in industrial wastewater. A great deal of studies have shown that excessive intake of copper is harmful to people's health [3]. The concentration of copper in drinking water recommended by the World Health Organization (WHO) is to be less than $1.5 \mathrm{mg} \cdot \mathrm{L}^{-1}$ [4]. Many articles reported the treatment methods of various wastewater containing $\mathrm{Cu}^{2+}$ [5], such as adsorption [6], ionexchange [7], coprecipitation [8], membrane filtration [9], electrochemical technology [10], reverse osmosis [11], etc. Heavy metal mainly exists in the form of ions in water, so it is more advantageous to remove heavy metal from wastewater by ion exchange method [12]. 
The most interesting is the combination of adsorption and ion-exchange methods, because the combined technology can not only greatly improve the removal efficiency, but also have selectivity for the target waste [13]. Therefore, the advanced materials with high porosity, perfect pore size distribution, and controllable ion-exchange capacity is urgently needed to be developed to improve the heavy metal removal efficiency [14].

Several types of porous inorganic materials [15] meeting the above standards have emerged in recent years, including clay [16], zeolite [17], montmorillonite [18], Prussian blue (PB) [19], Prussian blue analogues (PBAs) [20], etc. In particular, PB and PBAs are kinds of special metal-organic frameworks (MOFs) combined by transition metals (e.g., $\mathrm{Fe}^{2+}, \mathrm{Fe}^{3+}, \mathrm{Cu}^{2+}$, and $\left.\mathrm{Co}^{2+}\right)$ and $\mathrm{CN}^{-}$ligand. Different from most MOFs, $\mathrm{PB}$ has good water stability, organic solvent stability, and excellent organic solvent corrosion resistance, which makes it suitable for various solvent media [21]. Moreover, the perfect cubic structure framework of PB has the ability to substitute metal cations, so PB is considered to be an ideal adsorption material [22]. PB was effectively used to adsorb radioactive ions in the Chernobyl nuclear accident in 1987 and the Fukushima nuclear power plant leakage accident in 2011. Ishizaki et al. synthesized PB nanoparticles and studied the adsorption mechanism of $\mathrm{Cs}^{+}$by $\mathrm{PB}$, proving that $\mathrm{PB}$ is a promising adsorbent [23]. The synthesized $\mathrm{PB}$ based materials by Ohara et al. could quickly remove $\mathrm{Cs}^{+}$cations in water at less than $500 \mathrm{ppb} \mathrm{Cs}{ }^{+}$concentration in a few minutes [24]. It was proved that the removal of $\mathrm{Cs}^{+}$is carried out through two synergistic adsorption mechanisms: one is the physical adsorption inside the vacancy pores, and the other is the ion-exchange between $\mathrm{Cs}^{+}$and $\mathrm{Na}^{+}$. However, due to the small particle size and easy aggregation of $\mathrm{PB}$, the subsequent recovery of $\mathrm{PB}$ is a technical problem [25]. Therefore, recyclable and biodegradable PB-functionalized materials have become a research hotspot.

Cellulose fibers, being the most abundant and renewable biomass materials with certain specific surface area and good hydrophilicity, were demonstrated in application of wastewater treatment such as contaminant adsorption, membrane separation and catalysis fields [26]. They are very promising carriers of MOFs particles due to their biodegradability, recyclability and sustainability. However, the loading capacity of MOFs on some untreated cellulose fibers (e.g., pulp and cotton fibers) is not high enough and its adsorption performance is not outstanding due to the weak bonding strength between cellulose fibers and MOFs and the lack of bonding sites [27]. In order to solve this difficult problem, it is necessary to use new methods and strategies to develop cellulose fiber composite with high MOFs loading [28]. Some studies have been conducted to promote the growth and immobilization of MOFs on cellulose fibers to some extent by means of carboxymethylation [29,30], atomic layer deposition [31], carboxylation with citric acid [32], 3-glycidoxypropyltrimethoxysilane as linker [33,34], polydopamine as interface layer [35], etc. However, the depolymerization of cellulose fibers during carboxymethylation is unavoidable, and atomic layer deposition has a high requirement for equipment. There is an immediate need to seek a simple, efficient and general method to promote the growth and anchoring of MOFs on cellulose fibers while holding the inherent structure characteristics of cellulose fibers. Polymer coating is one of the common methods to construct multicomponent composites [36]. As one of common conductive polymers, polyaniline (PANI) has good chemical and thermal stability, low cost, easy synthesis and fast redox property, and in particular it exhibits superior adsorption abilities for most metal ions [37-40].

In the current work, we proposed a sustainable methodology of applying a novel and robust Prussian blue/polyaniline@cotton fibers (PB/PANI@CFs) composite, consisting of CFs as skeleton, PANI as intermediate coating and PB as adsorbent, for adsorption of copper ions. The current authors innovatively decorated CFs with the in-situ synthesized PANI as a binding coating to facilitate both the growth of $\mathrm{PB}$ and the uptake of $\mathrm{Cu}^{2+}$, thus imparting excellent $\mathrm{Cu}^{2+}$ adsorption capacity to the composite. Among the dopants, phytic acid (PA) is thought to be the most promising dopant for enhancing metal ion adsorption capability of PANI. PA, a cyclic molecule saturated with six dihydrogen phosphate, provides a strong binding affinity to metal ions. Therefore, the adsorption affinity of PANI would be 
further increased by incorporating PA molecules. For this reason, the doping of PA would be beneficial for enhancing the adsorption ability of PANI for metal ions [41-43]. With the assistance of PA, the acidic environment for the polymerization of aniline (ANI) was created and the PANI molecular chains were doped, PANI particles were coated in situ on $\mathrm{CFs}$, which increased the specific surface area and active sites of CFs. Then, $\mathrm{FeFe}(\mathrm{CN})_{6}$ nanoparticles with perfect cubic crystal structure were grown on the surface of PANI-coated $\mathrm{CFs}$ through the adsorption of amine and imine groups on PANI to $\mathrm{Fe}^{3+}$, as well as the chelation between some phosphate groups of PA and $\mathrm{Fe}^{3+}$ ions, and a PB/PANI@CFs composite was obtained (Scheme 1). Finally, the PB/PANI@CFs composite was used as an environment-friendly adsorbent to eliminate $\mathrm{Cu}^{2+}$ from wastewater.

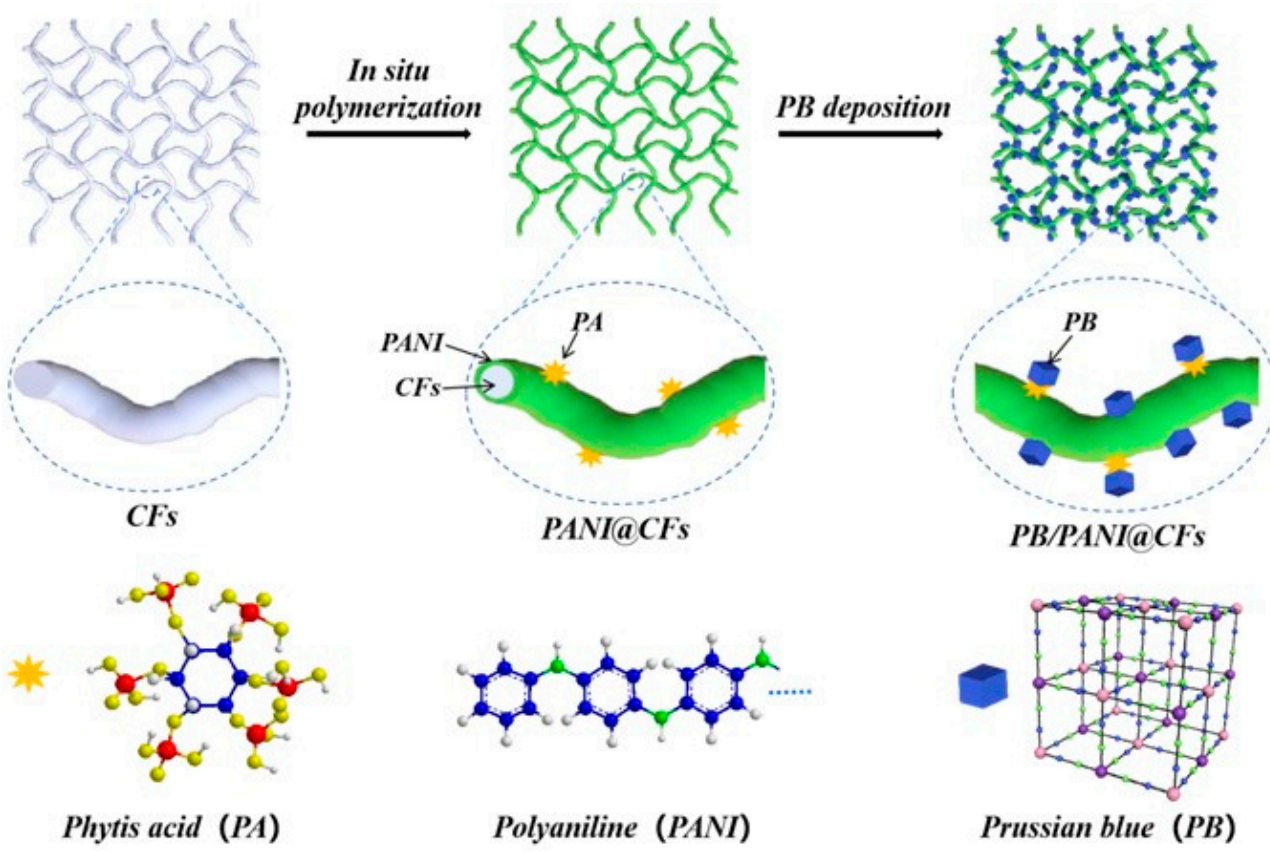

Scheme 1. Schematic illustration of preparation of PB/PANI@CFs.

\section{Materials and Methods}

\subsection{Materials}

CFs were provided by Yongsheng Cotton Textile Mill (Shijiazhuang, China), and boiled in boiling water for $4 \mathrm{~h}$ then dried at $60{ }^{\circ} \mathrm{C}$ before use. Aniline (analytically grade) and phytic acid $(\geq 70 \%)$ were produced by Sinopharm Chemical Reagent Co., Ltd. (Shanghai, China). Copper sulphate pentahydrate $(98 \%)$, potassium ferricyanide $(\geq 99.5 \%)$, and 5-sulfosalicylic acid dihydrate ( $\geq 99 \%)$ were manufactured by Aladdin Reagent Co., Ltd. (Shanghai, China). Ammonia (25-28\%) and ferric chloride hexahydrate (analytically grade) were produced by Macklin Reagent Co., Ltd. (Shanghai, China). Ammonium persulfate (analytically grade) was manufactured by Fuchen Chemical Reagent Co., Ltd. (Tianjin, China). Anhydrous ethanol (analytically grade) was produced by Tianjin Tianli Chemical Reagent Co., Ltd. (Tianjin, China). P-toluenesulfonic acid monohydrate (99\%) was manufactured by Shanghai Yien Chemical Technology Co., Ltd. (Shanghai, China). Hydrochloric acid (36-38\%) was produced by Xilong Scientific Co., Ltd. (Fujian, China). Sulfuric acid (98\%) was manufactured by Tianjin Fuyu Fine Chemical Co., Ltd. (Tianjin, China). Deionized water was self-made in our laboratory. The chemicals were directly used without further purification except aniline monomer was distilled under reduced pressure before use.

\subsection{Methods}

\subsubsection{Preparation of PANI@CFs Composite}

PANI@CFs composite was prepared by in situ polymerization method. Unless otherwise specified, the doping acid used in this study was phytic acid (PA). Typically, $2 \mathrm{~g}$ of 
oven-dried CFs (Figure 1a, $2 \mathrm{~cm} \times 2 \mathrm{~cm}$ ) were put into $160 \mathrm{~mL}$ deionized water, and $3 \mathrm{mmol}$ of PA were added. Then, $9 \mathrm{mmol}$ of aniline (ANI) dissolved in $10 \mathrm{~mL}$ of anhydrous ethanol were added to the mixture system. Next, $30 \mathrm{~mL}$ of deionized water containing $0.63 \mathrm{~g}$ of ammonium persulfate (APS) were dropwise added to the above system and continuously stirred in an ice bath for $4 \mathrm{~h}$ (the mass ratio of APS to ANI was 4:3). Finally, PA-doped PANI@CFs composite (Figure 1b) was obtained after washing with deionized water and drying at $60{ }^{\circ} \mathrm{C}$.

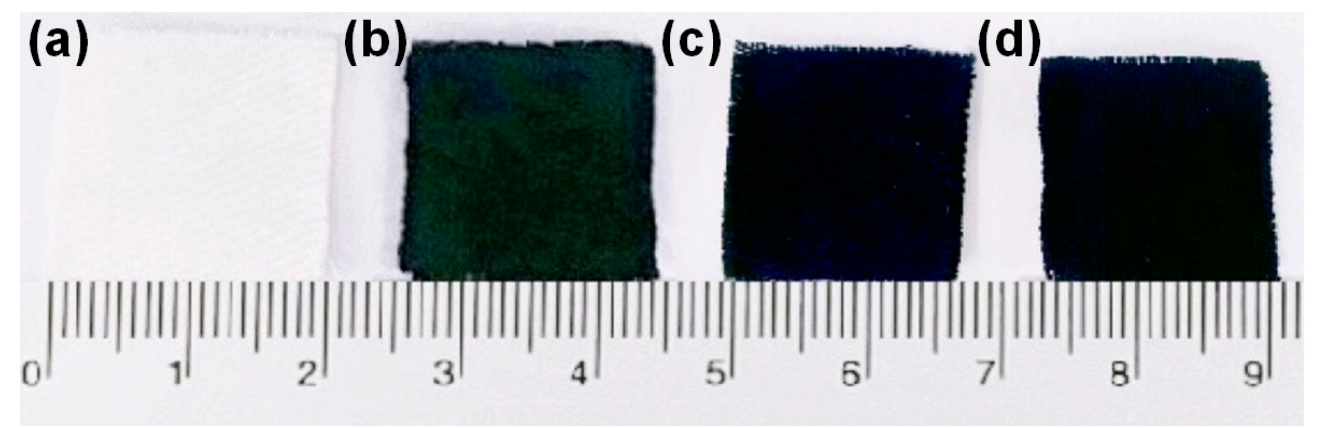

Figure 1. Digital photographs of CFs (a), PANI@CFs (b), PB@CFs (c) and PB/PANI@CFs (d).

\subsubsection{Preparation of PB@CFs Composite}

PB@CFs composite was fabricated via simple in-situ precipitation method. Typically, $2 \mathrm{~g}$ of oven-dried CFs were immersed in $150 \mathrm{~mL}$ of deionized water containing $1.5 \mathrm{~mol}$ potassium ferricyanide for $4 \mathrm{~h}$. Then, $1.5 \mathrm{~mol}$ of ferric chloride dissolved in $150 \mathrm{~mL}$ of deionized water were added and magnetically stirred at room temperature $\left(25^{\circ} \mathrm{C}\right)$ for $4 \mathrm{~h}$. Finally, PB@CFs composite (Figure 1c) was obtained after washing with deionized water and drying at $60^{\circ} \mathrm{C}$.

\subsubsection{Preparation of PB/PANI@CFs Composite}

PB/PANI@CFs composite (Figure 1d) was prepared through an in situ double-deposition method using PA as a doping acid. That is, PANI@CFs was firstly prepared by in situ synthesis process, and then PB was in situ deposited on the as-prepared PANI@CFs. For comparison, hydrochloric acid (HA), sulfuric acid (SA), p-toluenesulfonic acid (PTSA), and sulfosalicylic acid (SSA) doped PB/PANI@CFs composites (marked as PB/HA-PANI@CFs, PB/SA-PANI@CFs, PB/PTSA-PANI@CFs, and PB/SSA-PANI@CFs) were also prepared at $3 \mathrm{mmol}$ of doping acid with reference to similar procedure.

Prussian blue deposition ratio $(D, \%)$ was determined by the gravimetric method, and calculated by the formula calculated according to Equation (1).

$$
D=\left(W_{2}-W_{1}\right) / W_{0} \times 100 \%
$$

where $W_{0}$ is the weight of the original cotton fibers $(\mathrm{g}), W_{1}$ is the weight of the cotton fibers coated with PANI $(\mathrm{g})$, and $W_{2}$ is the weight of the cotton fibers deposited with PB $(\mathrm{g})$.

\subsubsection{Static Adsorption Experiment}

At room temperature, $1.0 \mathrm{~g}$ of the composites was put into beakers containing $2 \mathrm{mg} \cdot \mathrm{mL}^{-1}$ of copper sulphate solution, adjusted the $\mathrm{pH}$ value through dilute hydrochloric acid and sodium hydroxide solutions, and then vibrated on a constant temperature shaker for $5 \mathrm{~h}$. A certain amount of ammonia was added for complexation to make the copper ions undergo color reaction and was finally determined the UV-Vis spectra with a TU-1950 UV-Vis spectrometer (Beijing Purkinje General Instrument Co., Ltd., Beijing, China). The maximum absorption peak of $\mathrm{Cu}^{2+}$ appeared at about $607 \mathrm{~nm}$. 
The adsorption capacity $(Q)$ and removal efficiency $(R)$ of $\mathrm{Cu}^{2+}$ on the sample were calculated according to Equations (2) and (3), respectively.

$$
\begin{gathered}
Q=\left(C_{0}-C_{e}\right) \cdot V / m \\
R=\left(C_{0}-C_{e}\right) / C_{0} \times 100 \%
\end{gathered}
$$

where $Q$ is the adsorption capacity of $\mathrm{Cu}^{2+}\left(\mathrm{mg} \cdot \mathrm{g}^{-1}\right), C_{0}$ is the initial concentration of $\mathrm{Cu}^{2+}$ $\left(\mathrm{mg} \cdot \mathrm{mL}^{-1}\right), C_{e}$ is the concentration of $\mathrm{Cu}^{2+}$ in the solution when adsorption equilibrium was reached $\left(\mathrm{mg} \cdot \mathrm{mL}^{-1}\right), V$ is the volume of the solution $(\mathrm{mL}), m$ is the mass of adsorbent $(\mathrm{g})$, and $R$ is the removal efficiency of $\mathrm{Cu}^{2+}(\%)$.

\subsection{Characterization}

The surface morphology of the samples was analyzed by a scanning electron microscope (SEM) (Zeiss sigma 300, Carl Zeiss, Jena, Germany). The surface of each sample was coated with gold under vacuum before observation. The crystal structure of the samples was characterized by a X-ray diffractometer (XRD) (BrukerD8 advance, Bruker AXS, Karlsruhe, Germany). The functional groups of the samples were analyzed by a Fourier transform infrared spectrometer (FTIR) (Nicolet iS 50, Thermo Fisher, Shanghai, China). Chemical elements on the surface of the samples were analyzed by a X-ray photoelectron spectrometer (XPS) (EscaLab 250Xi, Thermo Fisher, Shanghai, China). The specific surface area and pore structure properties of the samples were studied using a micropore physisorption analyzer (ASAP 2020 HD88, Micromeritics Instrument Corp., Norcross, GA, USA) at liquid nitrogen temperature $(77 \mathrm{~K})$. The samples were degassed at $300{ }^{\circ} \mathrm{C}$ under vacuum for $4 \mathrm{~h}$ before testing. The specific surface area $\left(S_{\mathrm{BET}}\right)$ of the sample was calculated by Brunauer-Emmett-Teller (BET) method and the adsorption data of the corresponding isotherms in the relative pressure range from 0.04 to 0.32 . The total pore volume $\left(V_{\mathrm{t}}\right)$ of the sample was calculated from the nitrogen adsorption capacity at the relative pressure of $P / P_{0}=0.995$. The micropore volume $\left(V_{\text {micro }}\right)$ of the sample was calculated by t-plot method, and the mesoporous volume ( $\left.V_{\text {meso }}\right)$ of the sample was calculated by Barrett-Joyner-halenda (BJH) model.

\section{Results and Discussion}

\subsection{PANI Promoting Effect on PB Growth}

Figure 2a displays the effect of doping acid on PB deposition. It was found that PANI doped with various doping acids could promote the deposition of $\mathrm{PB}$ on CFs at different degrees, and the PANI doped with PA had the largest promoting effect, which might be attributed to chelation of PA with $\mathrm{Fe}^{3+}$ through some phosphate groups. Figure $2 \mathrm{~b}$ shows the effect of ANI dose on PB deposition, the deposition ratio of PB first increased then slightly decreased with increasing ANI dose and reached the highest at 9 mmol of ANI. This result indicated that an appropriate amount of PANI is beneficial to the deposition of $\mathrm{PB}$, but excessive PANI is unfavorable. Figure $2 \mathrm{c}$ displays the effect of PA dose on PB deposition, PB deposition ratio first increased with increasing PA dose from 1.5 to $3 \mathrm{mmol}$, and then decreased slightly with increasing PA dose from 3 to $4.5 \mathrm{mmol}$, which might be because the effective adsorption active sites of PANI were occupied by too many PA molecules. Figure $2 \mathrm{~d}$ shows the effect of $\mathrm{PB}$ growth time on PB deposition, PB deposition ratio first increased then decreased with prolonging growth time and reached the largest at $4 \mathrm{~h}$. 
(a)

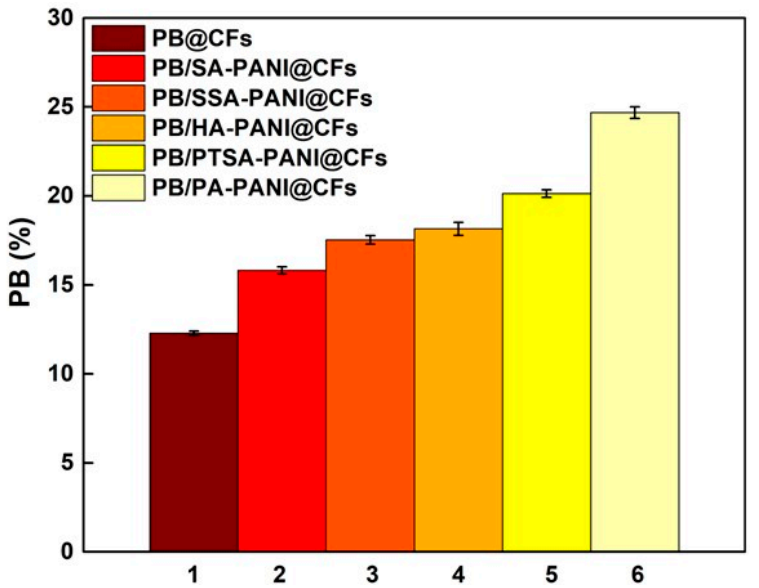

(c)

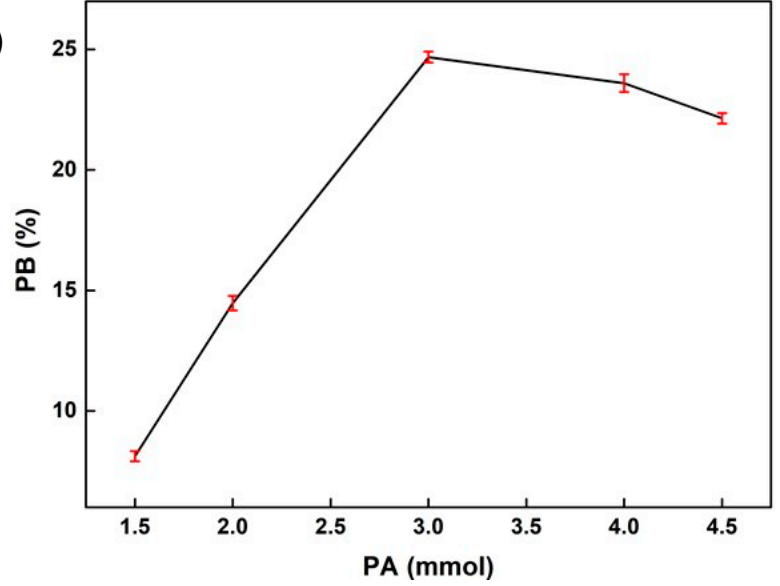

(b)

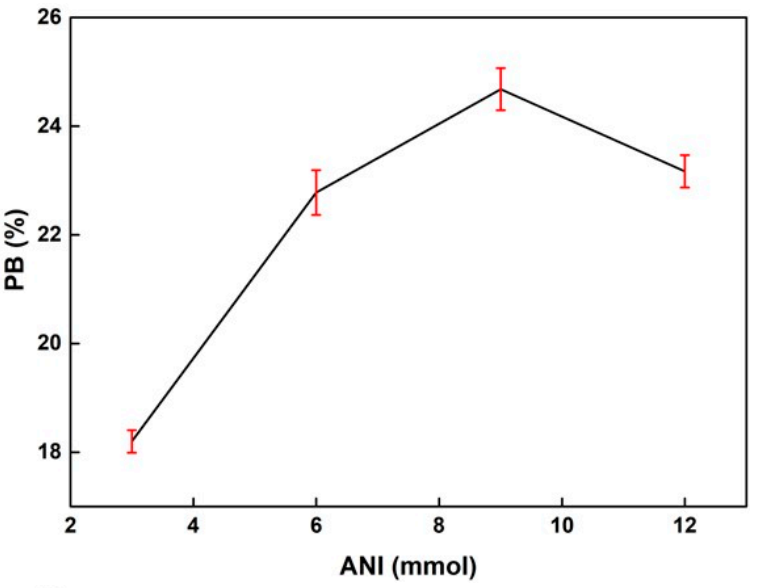

(d)

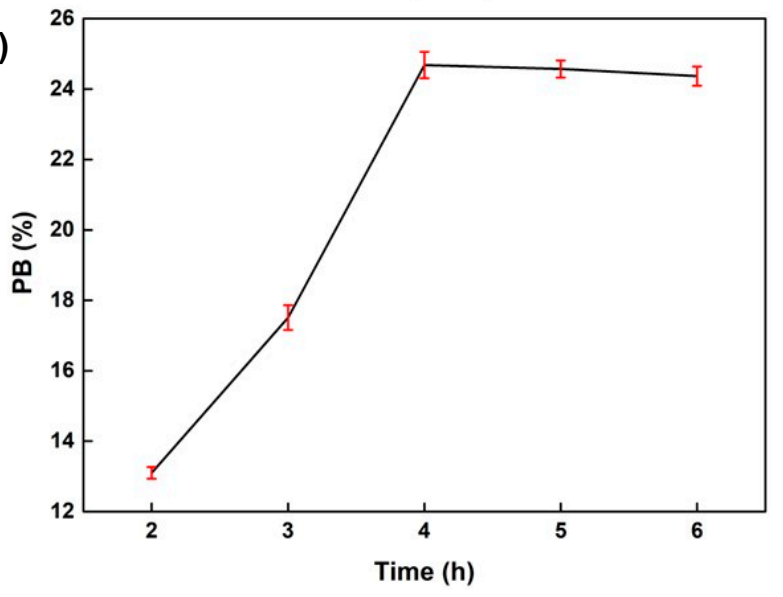

Figure 2. Effect of doping acid type (a), ANI dose (b), PA dose (c), and PB growth time (d) on $\mathrm{PB}$ deposition.

\subsection{Composite Characterization \\ 3.2.1. SEM Analysis}

Figure 3 displays the SEM images of PANI@CFs, PB@CFs, and PB/PANI@CFs at 20, 100, and $150 \mathrm{kx}$ magnifications. As shown in Figure 3a-c, PANI particles were synthesized in situ on cotton fibers and evenly dispersed. Pure $\mathrm{FeFe}(\mathrm{CN})_{6}$ particles are regular square blocks, which are typical Prussian blue particles. As seen from Figure $3 \mathrm{~d}-\mathrm{f}$, although $\mathrm{FeFe}(\mathrm{CN})_{6}$ particles were in situ synthesized and deposited on the surface of $\mathrm{CFs}$, obvious agglomeration was observed due to the low specific surface area of $\mathrm{CFs}$, so that their nano cubic structures were not obvious. In Figure $3 \mathrm{~g}-\mathrm{i}, \mathrm{FeFe}(\mathrm{CN})_{6}$ particles were in situ synthesized and densely and evenly deposited on the surface of PANI@CFs. There was no agglomeration of $\mathrm{FeFe}(\mathrm{CN})_{6}$ particles although the deposition amount of $\mathrm{FeFe}(\mathrm{CN})_{6}$ in PB/PANI@CFs was much higher than that in PB@CFs. The nanocube configuration of $\mathrm{FeFe}(\mathrm{CN})_{6}$ could be observed, which might be attributed to the fact that PANI increased the specific surface area of $\mathrm{CFs}$ and had a strong bonding with $\mathrm{FeFe}(\mathrm{CN})_{6}$. As seen from Figure 3a,d,g, compared with PANI@CFs and PB@CFs composites, the surface of PB/PANI@CFs composite was obviously smoother. 


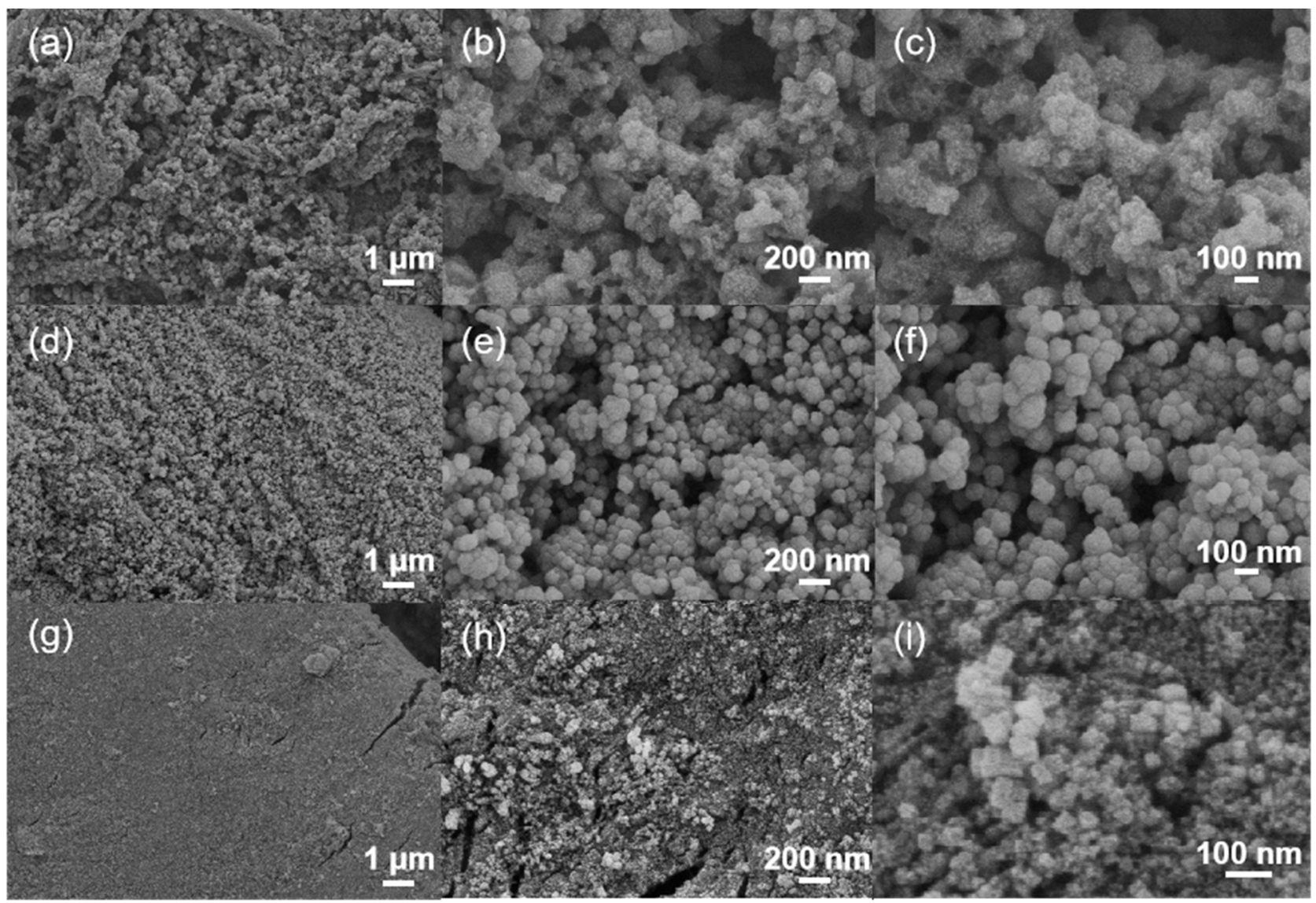

Figure 3. SEM images of PANI@CFs (a-c), PB@CFs (d-f), and PB/PANI@CFs (g-i) at 20, 100, and $150 \mathrm{kx}$ magnifications.

\subsubsection{XRD Analysis}

Figure 4a displays the XRD patterns of CFs, PANI@CFs, PB@CFs, and PB/PANI@CFs. The natural cotton fiber belongs to cellulose I monoclinic crystalline structure with $\mathrm{a}=0.834 \mathrm{~nm}$, $\mathrm{b}=1.04 \mathrm{~nm}, \mathrm{c}=0.789 \mathrm{~nm}$, and $\beta=83.2^{\circ}$. The characteristic diffraction peaks in the XRD pattern of $\mathrm{CFs}$ at $14.9^{\circ}, 16.3^{\circ}$, and $22.6^{\circ}$ were attributable to the (101), (10-1) and (002) crystal planes of cellulose I, respectively [44]. Compared with the XRD pattern of CFs, there was no obvious shift and peak shape change in the XRD pattern of PANI@CFs, confirming that the crystal structure of CFs had not changed after amorphous PANI coating. However, the peak intensity of PANI@CFs at $22.6^{\circ}$ was significantly greater than that of CFs, and the peak became sharper. This is because the regular macromolecular chains of PANI after doping were combined with $\mathrm{CFs}$, which improved the order of cellulose fiber crystal structure, reduced the structural defects and the amorphous regions, and increased the crystalline regions. $\mathrm{FeFe}(\mathrm{CN})_{6}$ has face-centered cubic lattice structure, high crystallinity, and no impurity phase. The characteristic peaks in the diffraction pattern of PB@CFs were well consistent with JCPDS Card No. 73-0687, as shown in Figure 4b, which indicated that $\mathrm{FeFe}(\mathrm{CN})_{6}$ crystals were successfully deposited on $\mathrm{CFs}$. In the XRD pattern of the PB/PANI@CFs composite, the diffraction peaks included all characteristic peaks of $\mathrm{CFs}$, PANI@CFs, and PB@CFs, confirming the amorphous PANI and crystalline PB had been successfully deposited on CFs. 


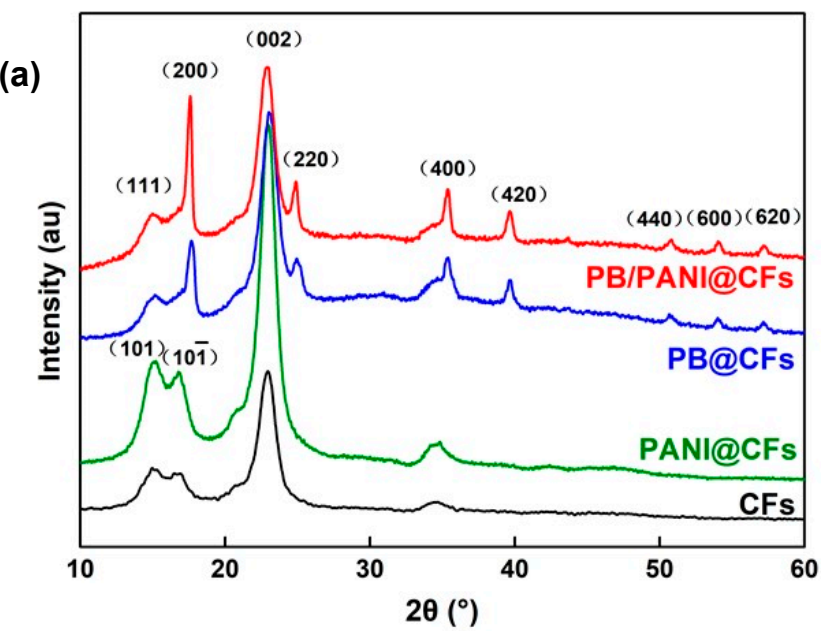

(b)

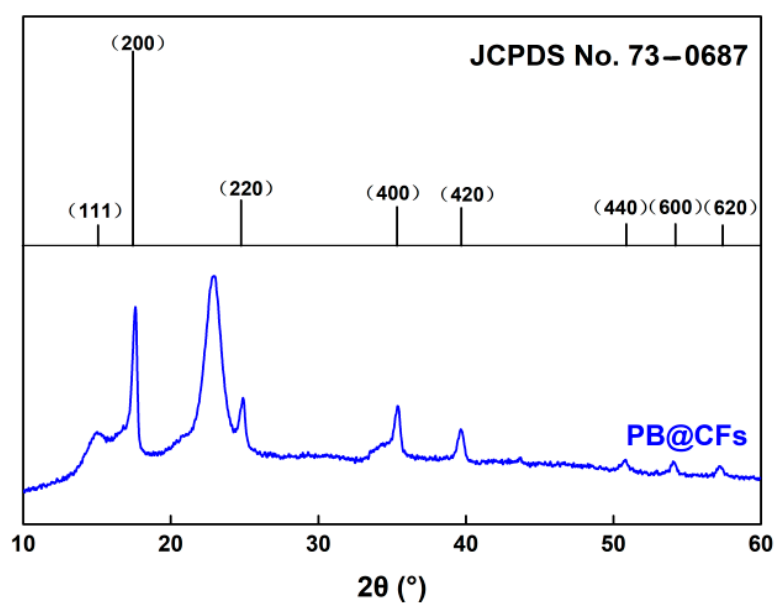

Figure 4. (a) XRD patterns of CFs, PANI@CFs, PB@CFs, and PB/PANI@CFs; (b) Comparison of PB@CFs XRD pattern with $\mathrm{FeFe}(\mathrm{CN})_{6}$ standard card JCPDS no. 73-0687.

\subsubsection{FTIR Analysis}

Figure 5a displays the FTIR spectra of CFs, PANI@CFs, PB@CFs, and PB/PANI@CFs in the region of 4000 to $400 \mathrm{~cm}^{-1}$. There were clear characteristic peaks of cellulose in the spectrum of CFs. The wide peak at about $3300 \mathrm{~cm}^{-1}$ belonged to the stretching vibration of $\mathrm{O}-\mathrm{H}$, and the stretching vibration peak of $\mathrm{C}-\mathrm{H}$ was at about $2880 \mathrm{~cm}^{-1}$. The strong absorption peaks at approximately 1160, 1106, and $1020 \mathrm{~cm}^{-1}$ belonged to the elastic vibrations of $\mathrm{C}-\mathrm{O}, \mathrm{C}-\mathrm{C}$ and $\mathrm{C}-\mathrm{O}-\mathrm{C}$, respectively. The absorption peaks at about 1487 and $1579 \mathrm{~cm}^{-1}$ in the spectrum of PANI@CFs might belong to the benzene type and quinone type structures in PANI, which could explain the oxidation state of PANI. The strong absorption bands at 2087 and $2170 \mathrm{~cm}^{-1}$ in the spectrum of PB@CFs belonged to $\mathrm{C} \equiv \mathrm{N}$ functional groups. The absorption bands in the far infrared region $\left(650\right.$ to $\left.450 \mathrm{~cm}^{-1}\right)$ were attributed to the bending characteristics of the $\mathrm{Fe}-\mathrm{C} \equiv \mathrm{N}-\mathrm{Fe}$ of $\mathrm{FeFe}(\mathrm{CN})_{6}$ [45], in which the peak at $588 \mathrm{~cm}^{-1}$ was the result of $\mathrm{Fe}-\mathrm{C}$ vibration. These characteristics indicated that $\mathrm{FeFe}(\mathrm{CN})_{6}$ was successfully deposited on $\mathrm{CFs}$. There were all characteristic peaks of PANI@CFs, PB@CFs and CFs in the spectrum of PB/PANI@CF, indicating that PANI and $\mathrm{FeFe}(\mathrm{CN})_{6}$ coexisted well on $\mathrm{CFs}$, which proved that PB/PANI@CFs composite was successfully prepared.
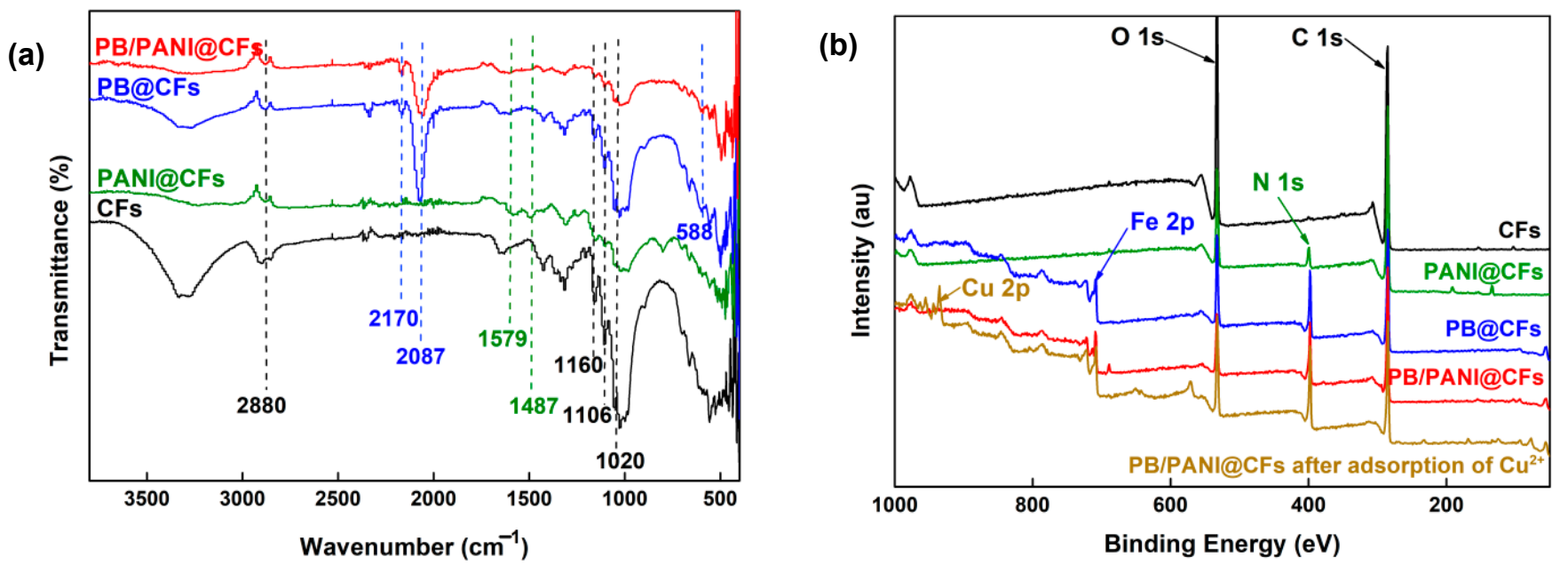

Figure 5. (a) FTIR spectra of CFs, PANI@CFs, PB@CFs, and PB/PANI@CFs, (b) XPS wide-scan spectra of CFs, PANI@CFs, PB@CFs, PB/PANI@CFs, and $\mathrm{Cu}^{2+}$-adsorbed PB/PANI@CFs. 


\subsubsection{XPS Analysis}

The XPS wide-scan spectra (Figure 5b) of CFs, PANI@CFs, PB@CFs, PB/PANI@CFs, and $\mathrm{Cu}^{2+}$-adsorbed PB/PANI@CFs further supplied a wealth of information about the chemical state of the elements on the surface of the composites. $\mathrm{C}$ and $\mathrm{O}$ peaks appeared in all samples, as displayed in Figure 5b, which was due to the carbon skeletons of organic compounds and the abundant hydroxyl groups of cellulose. In addition to the peaks of $\mathrm{C}$ and $\mathrm{O}$ elements, the $\mathrm{N}$ element peak appeared in PANI@CFs, and the Fe element peak appeared in PB@CFs. All the aforementioned elemental characteristic peaks appeared in PB/PANI@CFs, which showed that both PANI and PB were deposited on CFs and PB/PANI@CFs composite was successfully fabricated. The Cu element peak appeared in the PB/PANI@CFs treated with the copper wastewater, indicating that $\mathrm{Cu}^{2+}$ ions were successfully adsorbed on the surface of PB/PANI@CFs.

Figure 6a displays N 1s narrow-scan XPS spectrum of PANI@CFs, Figure 6b,c display $\mathrm{N}$ 1s and Fe 2p narrow-scan XPS spectra of PB@CFs, Figure 6d,e display N 1s and Fe 2p narrow-scan XPS spectra of PB/PANI@CFs and Figure 6f displays $\mathrm{Cu} 2 \mathrm{p}$ narrow-scan XPS spectrum of the $\mathrm{Cu}^{2+}$-adsorbed PB/PANI@CFs. The N 1s spectrum of PANI@CFs in Figure 6a could be fit into two peaks, around 399.39 and $401.44 \mathrm{eV}$, corresponded to $-\mathrm{NH}$ and $-\mathrm{N}^{+}-$bonds, respectively. In Figure $6 \mathrm{~b}, \mathrm{~d}$, in addition to the two peaks in Figure $6 \mathrm{a}$, there was a characteristic peak of metal nitride at about $397.65 \mathrm{eV}$, indicating iron ions existed in PB@CFs and PB/PANI@CFs composites. There were three obvious main peaks in Figure $6 \mathrm{c}, \mathrm{e}$, which corresponded to the energy spectrum of Fe 2p. Among them, the peaks at 708.48 and $710.24 \mathrm{eV}$ corresponded to the $\mathrm{Fe} 2 \mathrm{P} 3 / 2$ orbit, and the peaks at 721.38 and $724.96 \mathrm{eV}$ corresponded to the $\mathrm{Fe} 2 \mathrm{p} 1 / 2$ orbit [46]. In addition, there were two oscillating satellite peaks at 712.17 and $713.88 \mathrm{eV}$, indicating the existence of $\mathrm{Fe}^{3+}$ in $\mathrm{PB} @ \mathrm{CFs}$ and PB/PANI@CFs composites. In Figure 6f two characteristic absorption peaks of Cu 2P3/2 and $\mathrm{Cu} 2 \mathrm{p} 1 / 2$ appeared at 934.7 and $952.6 \mathrm{eV}$, and an obvious divalent copper satellite peak appeared at $943 \mathrm{eV}$, indicating that copper mainly existed in the form of divalent [47]. To sum up, PB/PANI@CFs composite was successfully prepared and effectively used to remove radioactive $\mathrm{Cu}^{2+}$ from wastewater.

\subsubsection{Nitrogen Adsorption Isotherm}

Nitrogen adsorption/desorption isotherms were measured to analyze the pore structural properties of the composites. The pore parameters of CFs, PANI@CFs, PB@CFs and PB/PANI@CFs are listed in Table 1. Figure 7a shows the nitrogen adsorption/desorption isotherms of the composites. All samples showed the typical type IV adsorption isotherm, and the areas enclosed by the curves were relatively small, hinting the existence of lots of mesopores. An increase in nitrogen adsorption was observed at relative pressure $P / P_{0}$ from 0.1 to 0.9 , which also indicated the existence of mesopores (average diameter of $6.9 \mathrm{~nm}$ ). This can be further verified by pore size distribution curves (Figure $7 \mathrm{~b}$ ). In addition, the isotherms showed a slight upward trend at high relative pressure of 0.9 to 1.0, which is related to the gaps between samples. As shown in Table 1, the BET surface area of PB/PANI@CFs is as high as $29.50 \mathrm{~m}^{2} \cdot \mathrm{g}^{-1}$, which is larger than those of CFs $\left(15.83 \mathrm{~m}^{2} \cdot \mathrm{g}^{-1}\right)$, PANI@CFs $\left(21.84 \mathrm{~m}^{2} \cdot \mathrm{g}^{-1}\right)$ and PB@CFs $\left(25.76 \mathrm{~m}^{2} \cdot \mathrm{g}^{-1}\right)$. The nitrogen adsorption/desorption isotherm results clearly illustrated the enhancement of the surface area by the incorporation of PANI and PB, which will be beneficial to the improvement of adsorption performance. 
(a)

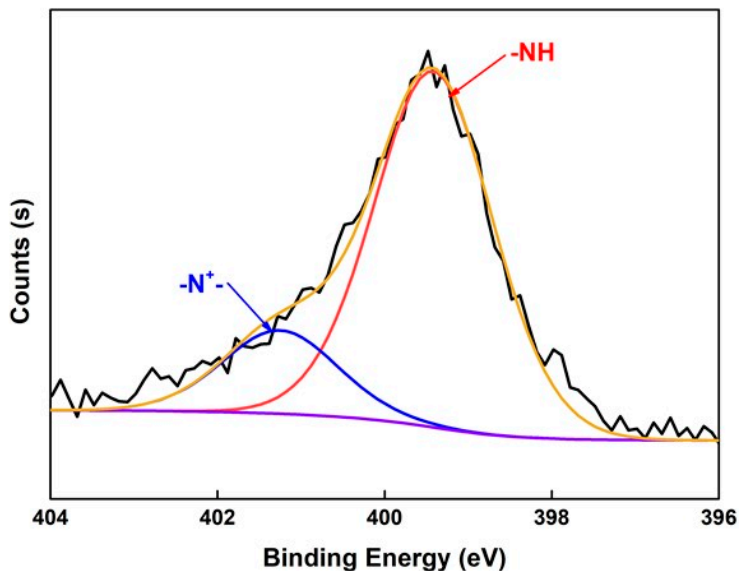

(c)

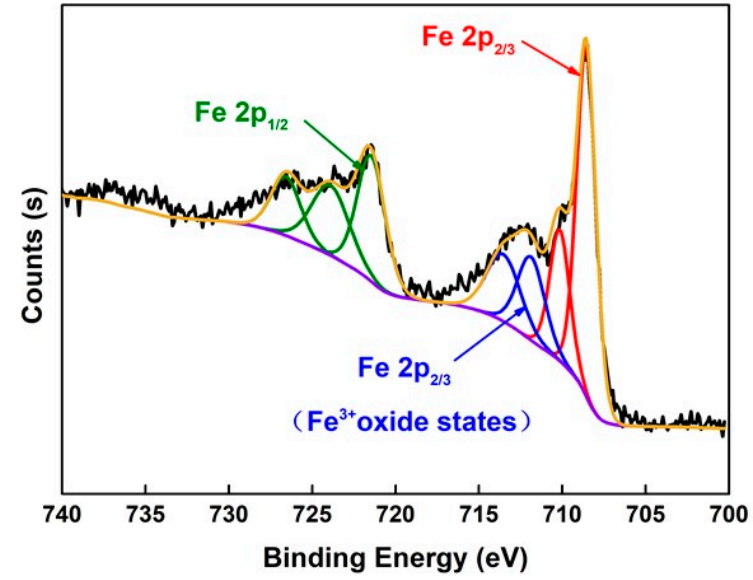

(e)

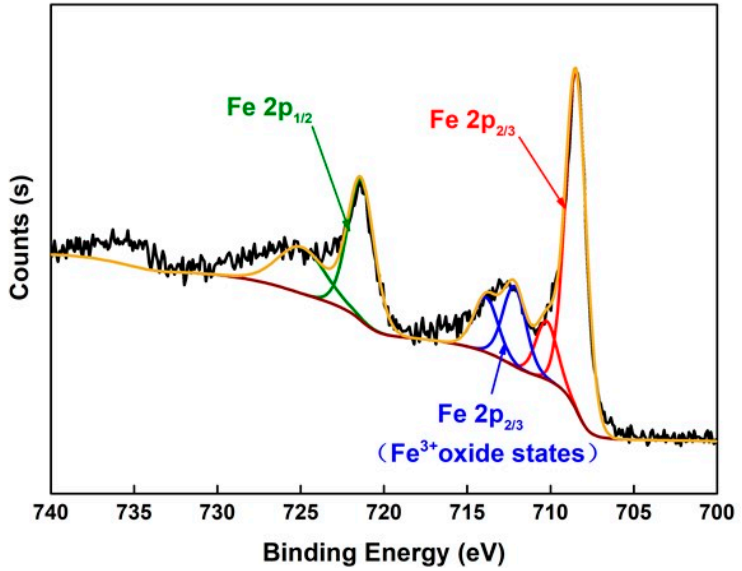

(b)

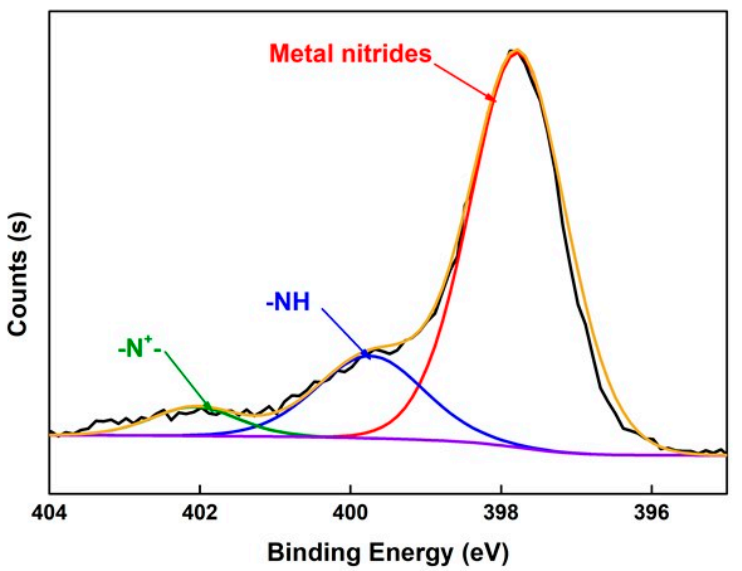

(d)

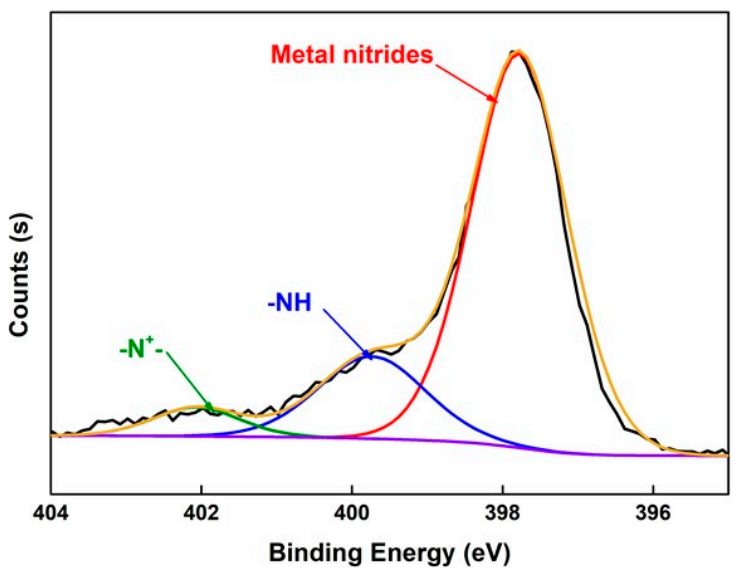

(f)

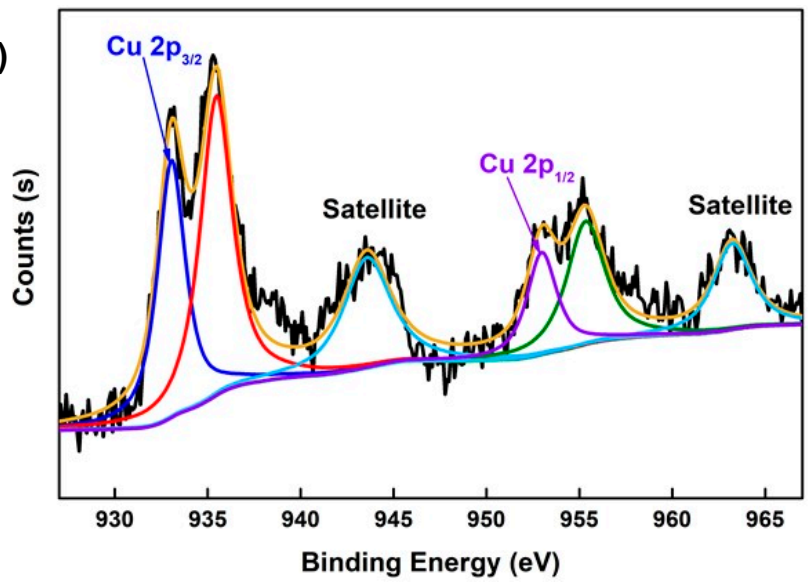

Figure 6. N 1s (a) narrow-scan XPS spectra of PANI@CFs; N 1s (b) and Fe 2p (c) narrow-scan XPS spectrum of PB@CFs; N 1s (d) and Fe 2p (e) narrow-scan XPS spectra of PB/PANI@CFs; and Cu 2p (f) narrow-scan XPS spectrum of $\mathrm{Cu}^{2+}$-adsorbed PB/PANI@CFs.

Table 1. Pore parameters of samples from nitrogen adsorption/desorption isotherms.

\begin{tabular}{ccccc}
\hline Sample & $\begin{array}{c}S_{\text {BET }} \\
\mathbf{m}^{\mathbf{2}} \cdot \mathbf{g}^{-\mathbf{1}}\end{array}$ & $\begin{array}{c}V_{\mathbf{T}} \\
\mathbf{c m}^{\mathbf{3}} \cdot \mathbf{g}^{-\mathbf{1}}\end{array}$ & $\begin{array}{c}V_{\text {micro }} \\
\mathbf{c m}^{\mathbf{3}} \cdot \mathbf{g}^{-\mathbf{1}}\end{array}$ & $\begin{array}{c}V_{\text {meso }} \\
\mathbf{c m}^{\mathbf{3}} \cdot \mathbf{g}^{\mathbf{1}}\end{array}$ \\
\hline CFs & 15.83 & 0.033 & 0.0066 & 0.035 \\
PANI@CFs & 21.84 & 0.044 & 0.0086 & 0.045 \\
PB@CFs & 25.76 & 0.051 & 0.0100 & 0.051 \\
PB/PANI@CFs & 29.50 & 0.054 & 0.0120 & 0.051 \\
\hline
\end{tabular}



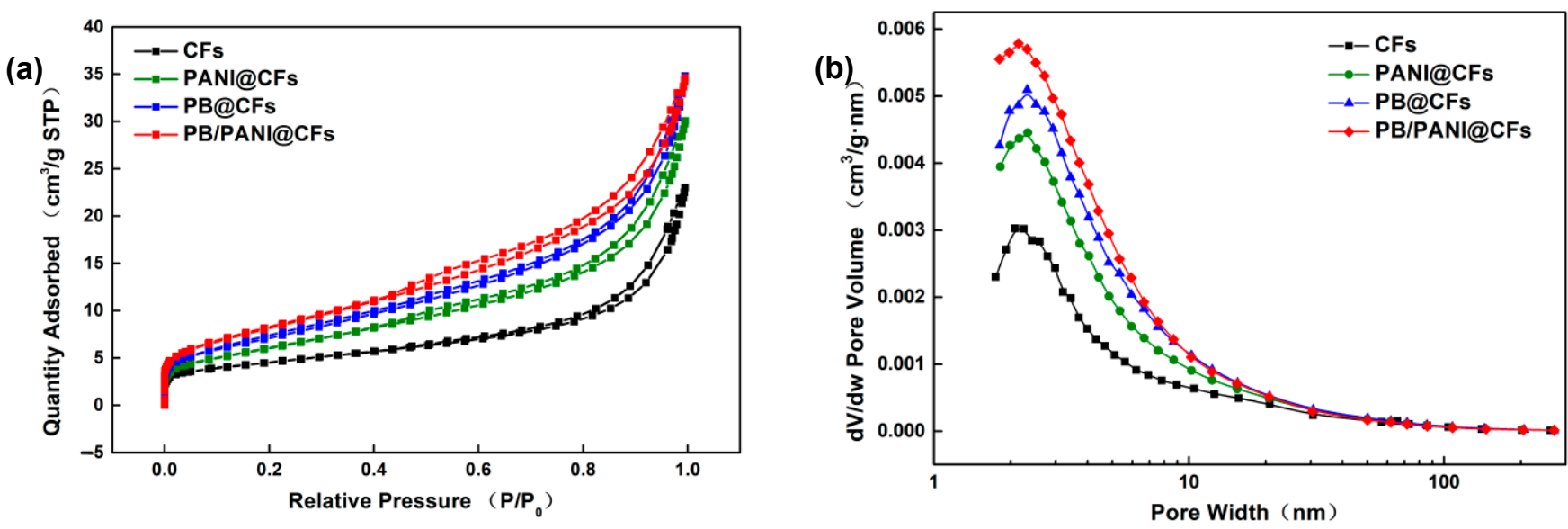

Figure 7. Nitrogen adsorption-desorption curves (a) and BJH mesopores (b) of CFs, PANI@CFs, PB@CFs and PB/PANI@CFs.

\subsection{Static Adsorption Study}

3.3.1. Influence of Adsorption Time on $\mathrm{Cu}^{2+}$ Adsorption Capacity and Adsorption Kinetic Models

At room temperature $\left(25^{\circ} \mathrm{C}\right)$, put $1.0 \mathrm{~g}$ of the composites into several beakers containing $25 \mathrm{~mL}$ of $2 \mathrm{mg} \cdot \mathrm{mL}^{-1}$ copper sulphate solution, adjusted initial $\mathrm{pH}$ to 5 , vibrated with a constant temperature shaker, and sampled at different vibration times to investigate the influence of adsorption time on $\mathrm{Cu}^{2+}$ adsorption capacity. As shown in Figure 8a, $\mathrm{Cu}^{2+}$ ions were quickly adsorbed by PB/PANI@CFs within $1 \mathrm{~h}$, which might be because there are more adsorption active sites on the surface of the adsorbent. The adsorption rate slowed down after $1 \mathrm{~h}$, which might be because the adsorption active sites on the adsorbent surface gradually decreased with the progress of adsorption. The adsorption of $\mathrm{Cu}^{2+}$ on PB/PANI@CFs almost reached equilibrium within $5 \mathrm{~h}$, and the measured adsorption capacity was $9.72 \mathrm{mg} \cdot \mathrm{g}^{-1}$. Compared with PB/PANI@CFs, the adsorption capacities of $\mathrm{Cu}^{2+}$ by the controls PB@CFs and PANI@CFs were much lower.

(a)

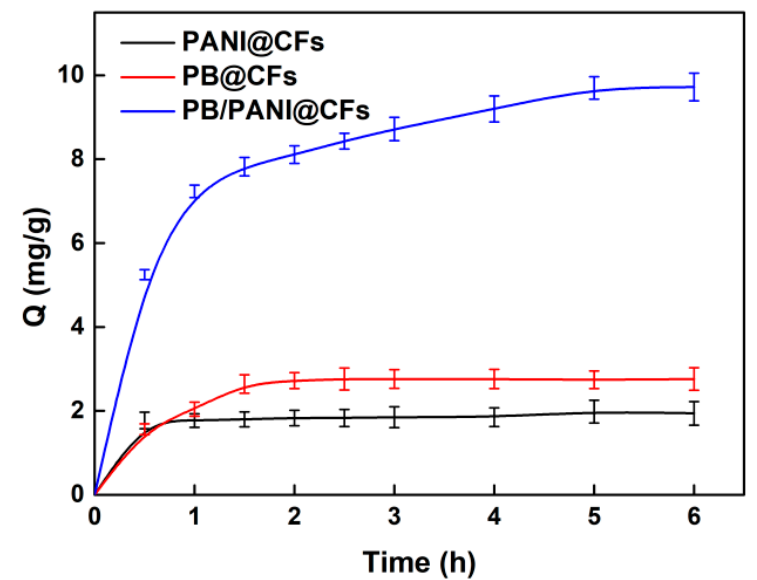

(b)

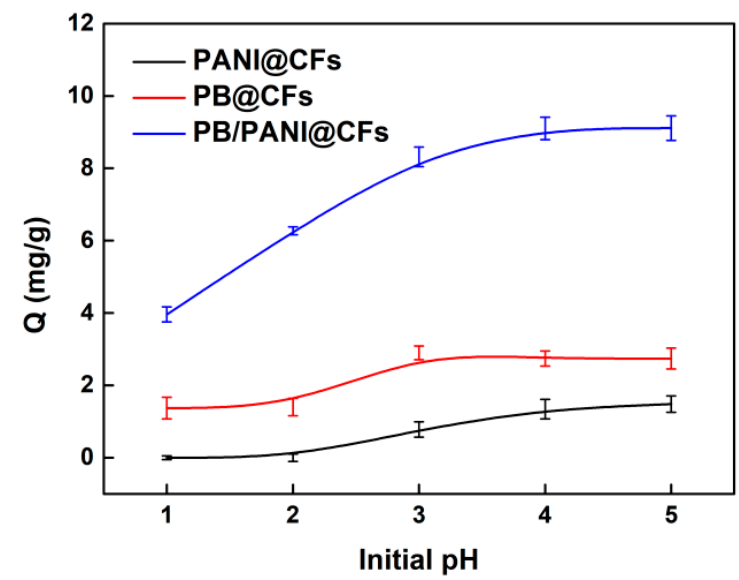

Figure 8. (a) Effect of adsorption time on $\mathrm{Cu}^{2+}$ adsorption capacity. Other conditions: $25^{\circ} \mathrm{C}, 1 \mathrm{~g}$ of adsorbent, $2 \mathrm{mg} \cdot \mathrm{mL}^{-1}$ of initial $\mathrm{CuSO}_{4}$ concentration, initial pH 5. (b) Effect of initial $\mathrm{pH}$ on $\mathrm{Cu}^{2+}$ adsorption capacity. Other conditions: $25^{\circ} \mathrm{C}, 5 \mathrm{~h}$ of absorption time, $1 \mathrm{~g}$ of adsorbent, $2 \mathrm{mg} \cdot \mathrm{mL}^{-1}$ of initial $\mathrm{CuSO}_{4}$ concentration. 
The mechanism of action between PB/PANI@CFs and $\mathrm{Cu}^{2+}$ was further studied by using pseudo-first order (Equation (4)) and pseudo-second order (Equation (5)) kinetic models [48].

$$
\begin{gathered}
\ln \left(q_{e}-q_{t}\right)=\ln q_{e}-k_{1} t \\
t / q_{t}=1 /\left(k_{2} \cdot q_{e}{ }^{2}\right)+t / q_{e}
\end{gathered}
$$

where, $q_{e}$ and $q_{t}$ represent the equilibrium adsorption capacity and the adsorption capacity at time $t$, respectively, $\mathrm{mg} \cdot \mathrm{g}^{-1} ; t$ is the adsorption time, $\mathrm{h} ; k_{1}$ is the constant of the pseudofirst order kinetic model, $\mathrm{h}^{-1} ; k_{2}$ is the constant of the pseudo-second order kinetic model, $\mathrm{mg} \cdot \mathrm{g}^{-1} \cdot \mathrm{h}^{-1}$.

The rate-limiting step is mainly diffusion for the pseudo-first order model, whereas the rate-controlling step is mainly chemical reaction for the pseudo-second order model [49]. Compared Figure 9a with Figure 9b, the adsorption of $\mathrm{Cu}^{2+}$ by PB/PANI@CFs was more consistent with the pseudo-second order kinetic model. The kinetic model parameters of $\mathrm{Cu}^{2+}$ adsorption by PB/PANI@CFs are listed in Table 2. The correlation coefficient of the pseudo-second order kinetic model was 0.993 , which was higher than that of the pseudo-first order kinetic model (0.855). This suggests that the pseudo-second order model, based on the assumption that the rate-controlling step may be chemical adsorption or chemisorption involving valency forces through sharing/exchange of electrons between adsorbent and adsorbate [49], provided the best correlation between predicted and measured values. Therefore, the adsorption process of $\mathrm{Cu}^{2+}$ on PB/PANI@CFs followed the pseudo-second order kinetic model. The predicted equilibrium adsorption capacity of $10.17 \mathrm{mg} \cdot \mathrm{g}^{-1}$ was almost equal to the experimentally measured value $\left(9.72 \mathrm{mg} \cdot \mathrm{g}^{-1}\right)$.

(a)

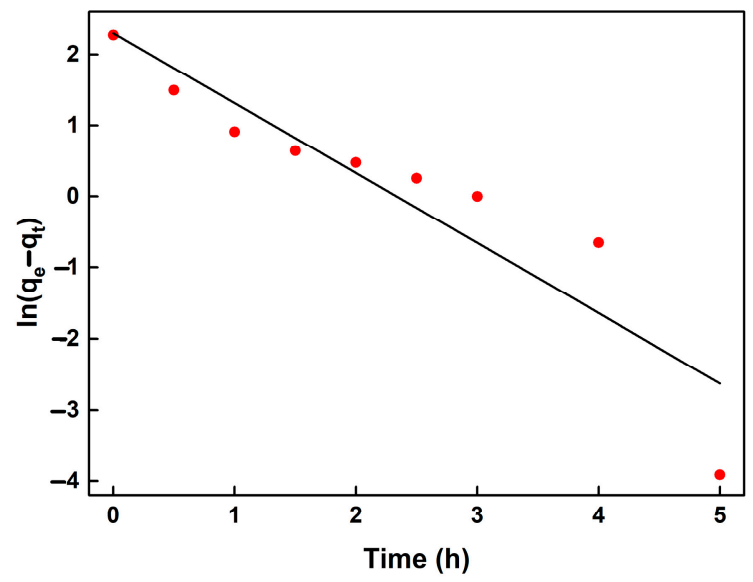

(b)

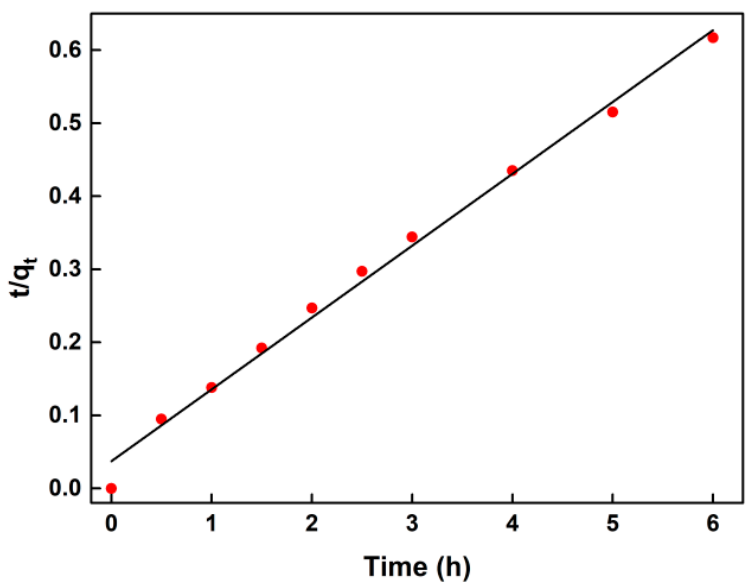

Figure 9. Pseudo-first order (a) and pseudo-second order (b) kinetic models of $\mathrm{Cu}^{2+}$ adsorption by PB/PANI@CFs.

Table 2. Kinetic model parameters of $\mathrm{Cu}^{2+}$ adsorption by PB/PANI@CFs.

\begin{tabular}{cccccc}
\hline \multicolumn{3}{c}{ Pseudo-First Order Kinetic } & \multicolumn{3}{c}{ Pseudo-Second Order Kinetic } \\
\hline$k_{1}\left(\mathrm{~h}^{-1}\right)$ & $q_{e}\left(\mathrm{mg} \cdot \mathrm{g}^{-1}\right)$ & $R^{2}$ & $k_{2}\left(\mathrm{mg} \cdot \mathrm{g}^{-1} \cdot \mathrm{h}^{-1}\right)$ & $q_{e}\left(\mathrm{mg} \cdot \mathrm{g}^{-1}\right)$ & $R^{2}$ \\
0.9855 & 9.98 & 0.855 & 0.2598 & 10.17 & 0.993 \\
\hline
\end{tabular}

\subsubsection{Influence of Initial $\mathrm{pH}$ on $\mathrm{Cu}^{2+}$ Adsorption Capacity}

At room temperature, we put $1.0 \mathrm{~g}$ of the composites into several beakers containing $25 \mathrm{~mL}$ of $2 \mathrm{mg} \cdot \mathrm{mL}^{-1}$ copper sulphate solution, adjust the initial $\mathrm{pH}$ values with dilute hydrochloric acid and sodium hydroxide solutions, and vibrate on a constant temperature shaker for $5 \mathrm{~h}$ to investigate the influence of initial $\mathrm{pH}$ on $\mathrm{Cu}^{2+}$ adsorption capacity. As displayed in Figure 8b, the adsorption capacity of $\mathrm{Cu}^{2+}$ increased with increasing initial 
pH value, especially for PB/PANI@CFs. When the solution is acidic, a large number of $\mathrm{H}^{+}$ ions in the solution will form competitive adsorption with $\mathrm{Cu}^{2+}$, thus affecting the removal of $\mathrm{Cu}^{2+}$ [50]. Conversely, $\mathrm{Cu}^{2+}$ will form blue copper hydroxide precipitates in the solution with initial $\mathrm{pH} \geq 5.7$. So, initial $\mathrm{pH} 5$ is the best solution environment.

\subsubsection{Influence of Adsorbent Dose on $\mathrm{Cu}^{2+}$ Adsorption Capacity}

At a room temperature of $25^{\circ} \mathrm{C}$, put $0.01,0.02,0.05,0.1,0.2,0.5,0.8,1.0,1.2,1.4,1.6$ and $1.8 \mathrm{~g}$ of the composites into several beakers containing $2 \mathrm{mg} \cdot \mathrm{mL}^{-1}$ copper sulphate solution, adjusted initial $\mathrm{pH}$ to 5 , and vibrated for $5 \mathrm{~h}$ to investigate the influence of adsorbent dose on $\mathrm{Cu}^{2+}$ adsorption capacity $(Q)$ and removal efficiency $(R)$. The results in Figure 10b showed that the larger the adsorbent dose was, the more obvious the removal effect was, and the maximum removal efficiency reached $93.4 \%$ for PB/PANI@CFs. However, the unit adsorption capacity gradually decreased with increasing adsorbent dose, and the optimal unit adsorption capacity could reach $31.93 \mathrm{mg} \cdot \mathrm{g}^{-1}$ for PB/PANI@CFs (Figure 10a).

(a)

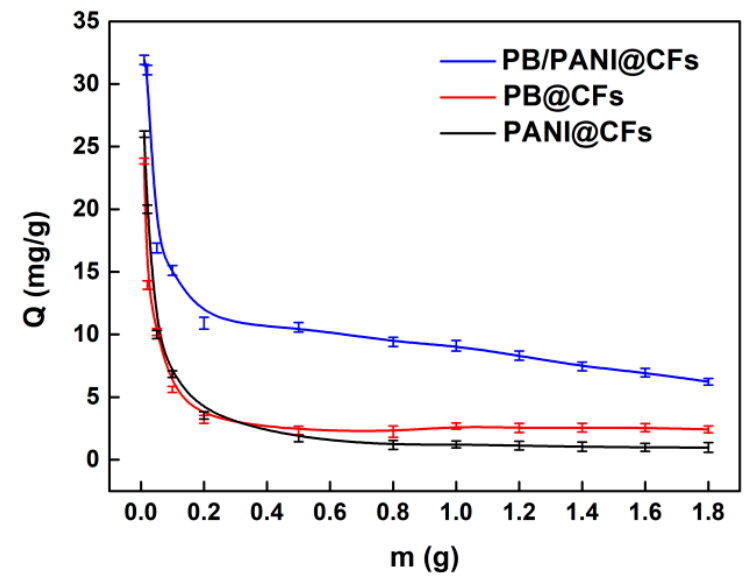

(b)

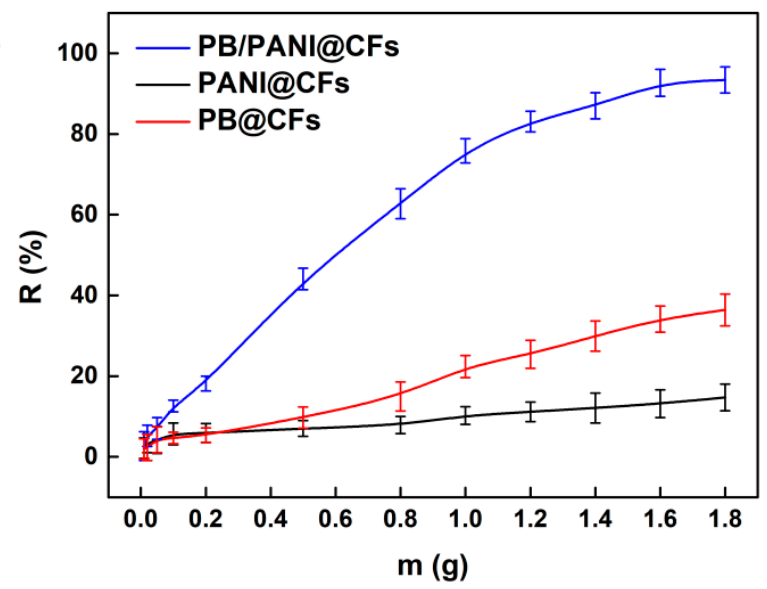

Figure 10. Effect of adsorbent dose on adsorption capacity (a) and removal efficiency (b) of $\mathrm{Cu}^{2+}$. Other conditions: $25^{\circ} \mathrm{C}, 5 \mathrm{~h}$ of absorption time, $2 \mathrm{mg} \cdot \mathrm{mL}^{-1}$ of initial $\mathrm{CuSO}_{4}$ concentration, initial pH 5.

3.3.4. Influence of Initial Copper Sulfate Concentration on Adsorption Capacity and Isothermal Adsorption Models

We prepared copper sulfate solutions of different concentrations, put $1.0 \mathrm{~g}$ of the composites to the above as-prepared copper sulphate solutions, adjusted initial $\mathrm{pH}$ to 5 , and vibrated at $25^{\circ} \mathrm{C}$ for $5 \mathrm{~h}$ in a constant temperature shaker to investigate the influence of initial $\mathrm{CuSO}_{4}$ concentration on adsorption capacity. The results are shown in Figure 11a. For PB/PANI@CFs, the adsorption capacity of $\mathrm{Cu}^{2+}$ increased from 6.51 to $23.54 \mathrm{mg} \cdot \mathrm{g}^{-1}$ with increasing initial $\mathrm{CuSO}_{4}$ concentration from 1 to $10 \mathrm{mg} \cdot \mathrm{mL}^{-1}$, but the adsorption capacity basically remained unchanged with the further increase of initial $\mathrm{CuSO}_{4}$ concentration. For the controls (PB@CFs and PANI@CFs), their adsorption capacities had the same change trend except for the lower numerical values. The surface adsorption of $\mathrm{Cu}^{2+}$ on the composites was almost saturated with the increase of initial $\mathrm{CuSO}_{4}$ concentration, the exchangeable cations are also completely exchanged with $\mathrm{Cu}^{2+}$ in the solution, and the adsorption capacity tends to be unchanged.

The adsorption isotherm describes the adsorption phase equilibrium diagram. Through calculation and drawing on the adsorption isotherm, the relationship between equilibrium adsorption capacity of $\mathrm{Cu}^{2+}$ on PB/PANI@CFs and $\mathrm{Cu}^{2+}$ equilibrium concentration at a given temperature can be intuitively presented, and the adsorption mechanism can be preliminarily judged. The change in the equilibrium adsorption capacity of $\mathrm{Cu}^{2+}$ on PB/PANI@CFs with $\mathrm{Cu}^{2+}$ equilibrium concentration at $25^{\circ} \mathrm{C}$ is given in Figure $11 \mathrm{~b}$. This is the characteristic of type IV adsorption isotherm according to Brunauer classification [51]. Such isotherm is indicative of relatively strong adsorbent-adsorbate interactions in the 
PB/PANI@CFs-Cu ${ }^{2+}$ system, implying that the dominant adsorption mechanism of $\mathrm{Cu}^{2+}$ on PB/PANI@CFs is a chemical reaction (e.g., ion-exchange). The result from the adsorption isotherm is consistent with that from the adsorption kinetic study as described in the previous section.
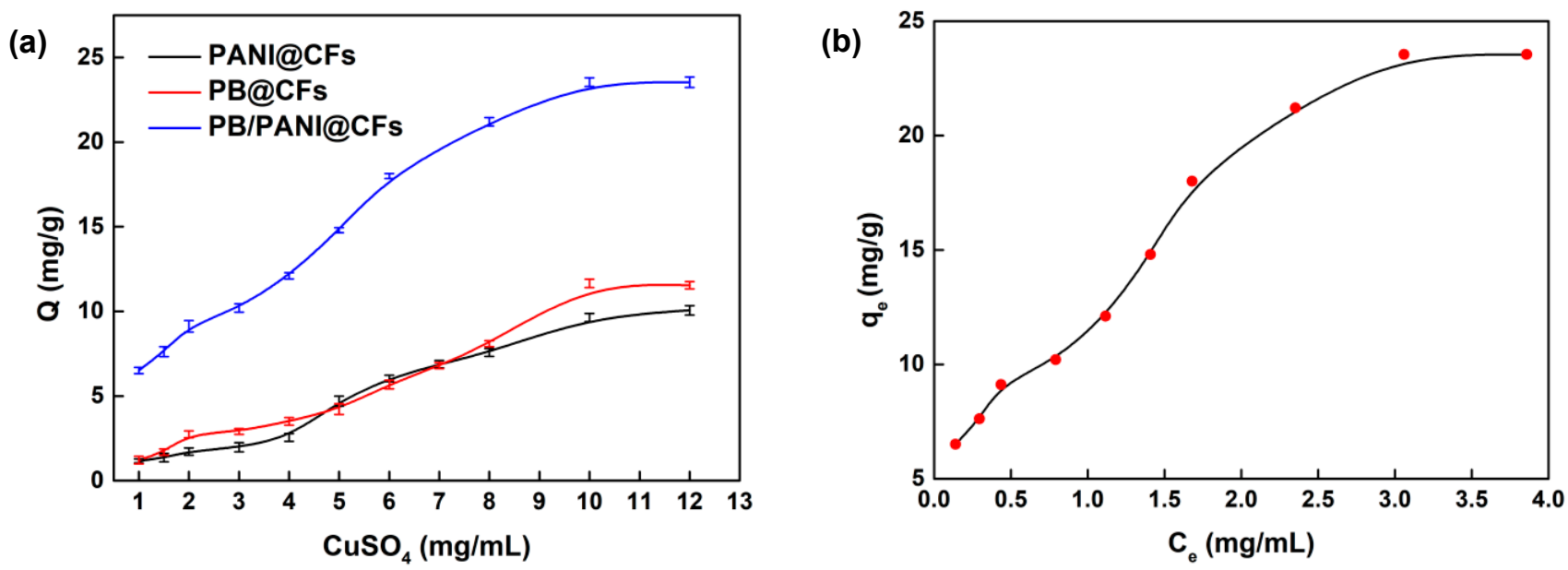

Figure 11. (a) Effect of initial $\mathrm{CuSO}_{4}$ concentration on adsorption capacity, (b) Change of equilibrium adsorption capacity of $\mathrm{Cu}^{2+}$ on $\mathrm{PB} / \mathrm{PANI} @ \mathrm{CFs}$ with $\mathrm{Cu}^{2+}$ equilibrium concentration. Other conditions: $25^{\circ} \mathrm{C}, 1 \mathrm{~g}$ of adsorbent dose, $5 \mathrm{~h}$ of absorption time, initial $\mathrm{pH} 5$.

In the adsorption experiment, the isothermal adsorption models can be used to evaluate the adsorption behavior of adsorbent to adsorbate. The adsorption experimental data of PB/PANI@CFs under different initial $\mathrm{CuSO}_{4}$ concentrations were treated according to the Freundlich (Equation (6)) and Langmuir (Equation (7)) isothermal adsorption equations [52].

$$
\begin{aligned}
\ln q_{e} & =\ln K_{F}+\frac{1}{n} \ln C_{e} \\
\frac{C_{e}}{q_{e}} & =\frac{1}{K_{L} q_{m}}+\frac{C_{e}}{q_{m}}
\end{aligned}
$$

where, $q_{e}$ is the adsorption capacity of $\mathrm{Cu}^{2+}$ under different initial $\mathrm{CuSO}_{4}$ concentrations, $\mathrm{mg} \cdot \mathrm{g}^{-1} ; q_{m}$ is the maximum adsorption capacity, $\mathrm{mg} \cdot \mathrm{g}^{-1} ; C_{e}$ is the concentration of residual $\mathrm{Cu}^{2+}$ at adsorption equilibrium, $\mathrm{mg} \cdot \mathrm{mL}^{-1} ; K_{F}$ and $n$ are the constants related to the Freundlich isothermal adsorption, and the unit of $K_{F}$ is $\left(\mathrm{mg} \cdot \mathrm{g}^{-1}\right) /(\mathrm{L} \cdot \mathrm{mg})^{1 / n} ; K_{L}$ is the Langmuir isotherm constant, $\mathrm{L} \cdot \mathrm{mg}^{-1}$.

Based on the fitted isotherms from Table 3 and Figure 12, higher $R^{2}$ value (0.954) was obtained from the Freundlich model compared with that from the Langmuir model (0.926) on PB/PANI@CFs, suggesting that the Freundlich adsorption isotherm equation was more suitable for the description of the adsorption process of $\mathrm{Cu}^{2+}$ on PB/PANI@CFs, and the adsorption of $\mathrm{Cu}^{2+}$ on PB/PANI@CFs seemed to belong to the multilayer adsorption on the heterogeneous surface [24]. Generally speaking, a Freundlich constant $n$ between 1 and 10 means that the adsorption is favorable, and a larger value of $n$ indicates stronger interaction between metal ions and the adsorbent $[53,54]$. It can be seen that the $n$ value in Table 3 is 2.32 , implying that the adsorption process for $\mathrm{Cu}^{2+}$ onto PB/PANI@CFs was favorable.

Table 3. Isotherm parameters of adsorption of $\mathrm{Cu}^{2+}$ by PB/PANI@CFs.

\begin{tabular}{cccccc}
\hline \multicolumn{3}{c}{ Freundlich } & \multicolumn{3}{c}{ Langmuir } \\
\hline$n$ & $K_{F}$ & $R^{2}$ & $q_{m}\left(\mathrm{mg} \cdot \mathrm{g}^{-1}\right)$ & $K_{L}\left(\mathrm{~L} \cdot \mathrm{mg}^{-1}\right)$ & $R^{2}$ \\
2.32 & {$\left[\left(\mathrm{mg} \cdot \mathrm{g}^{-1}\right) /(\mathrm{L} \cdot \mathrm{mg})^{1 / n}\right]$} & 0.954 & 27.39 & 1.09 & 0.926 \\
\hline
\end{tabular}


(a)

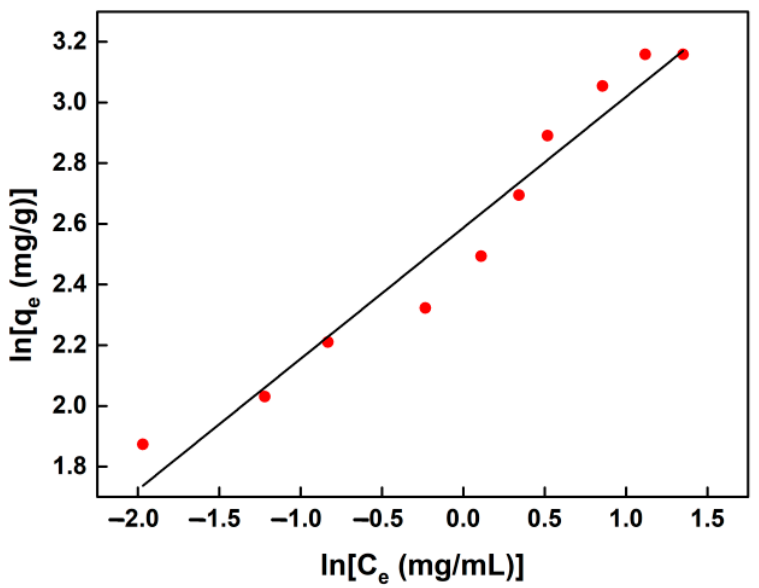

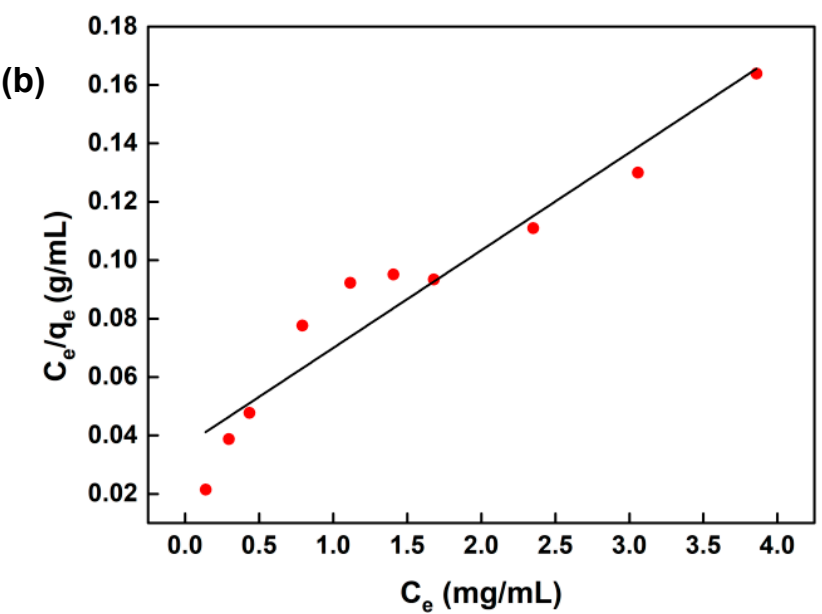

Figure 12. Freundlich (a) and Langmuir (b) isotherm adsorption models of PB/PANI@CFs.

\section{Conclusions}

A novel cellulose-based adsorbent (PB/PANI@CFs) was successfully prepared by a two-step in-situ deposition method, and PA-doped PANI as a bonding coating promoted both the growth of $\mathrm{PB}$ and the uptake of $\mathrm{Cu}^{2+}$. The deposition ratio of $\mathrm{PB}$ is as high as $24.68 \%$ when ANI is $9 \mathrm{mmol}$, PA is $2 \mathrm{~mL}$, and $\mathrm{PB}$ deposition time is $4 \mathrm{~h}$. The adsorption capacity of $\mathrm{Cu}^{2+}$ on PB/PANI@CFs increased with adsorption time, and reached equilibrium in about $5 \mathrm{~h}$. The initial $\mathrm{pH}$ had a certain influence on $\mathrm{Cu}^{2+}$ removal, and the removal efficiency was the highest under weak acidic conditions. The maximum removal efficiency could reach $93.4 \%$, and the maximum adsorption capacity could reach $31.93 \mathrm{mg} \cdot \mathrm{g}^{-1}$. The adsorption of $\mathrm{Cu}^{2+}$ on PB/PANI@CFs followed the pseudo-second order kinetic model indicating that chemisorption was the rate-determining step, and conformed to the Freundlich adsorption isothermal model implying that the adsorption seemed to belong to the multilayer adsorption on the heterogeneous surface. This new composite biomaterial is expected to be used as an efficient adsorbent for wastewater treatment such as copper ion removal.

Author Contributions: Conceptualization and methodology, X.W. and X.Q.; formal analysis, D.Y. and X.A.; investigation, X.W. and Q.L.; data curation, X.W.; writing — original draft preparation, X.W.; writing-review and editing, X.Q.; supervision, D.Y., X.A. and X.Q. All authors have read and agreed to the published version of the manuscript.

Funding: This research was funded by the National Natural Science Foundation of China, Grant Number 31770620.

Institutional Review Board Statement: Not applicable.

Informed Consent Statement: Not applicable.

Data Availability Statement: The authors confirm that the data supporting the findings of this study is available within the article.

Acknowledgments: The authors wish to acknowledge the support of the National Natural Science Foundation of China (Grant No. 31770620).

Conflicts of Interest: The authors declare no conflict of interest.

\section{References}

1. Zamora-Ledezma, C.; Negrete-Bolagay, D.; Figueroa, F.; Zamora-Ledezma, E.; Ni, M.; Alexis, F.; Guerrero, V.H. Heavy metal water pollution: A fresh look about hazards, novel and conventional remediation methods. Environ. Technol. Innov. 2021, 22, 101504. [CrossRef]

2. Hänninen, H.; Forsström, A.; Yagodzinskyy, Y. Copper behavior in geological nuclear waste disposal. In Nuclear Corrosion: Research, Progress and Challenges; Woodhead Publishing: Cambridge, UK, 2020; pp. 391-402. 
3. Wang, J.; Dang, M.; Duan, C.; Zhao, W.; Wang, K. Carboxymethylated cellulose fibers as low-cost and renewable adsorbent materials. Ind. Eng. Chem. Res. 2017, 56, 14940-14948. [CrossRef]

4. Zhu, B.; Fan, T.; Zhang, D. Adsorption of copper ions from aqueous solution by citric acid modified soybean straw. J. Hazard. Mater. 2008, 153, 300-308. [CrossRef] [PubMed]

5. Manos, M.J.; Malliakas, C.D.; Kanatzidis, M.G. Heavy-metal-ion capture, ion-exchange, and exceptional acid stability of the open-framework chalcogenide $\left(\mathrm{NH}_{4}\right)_{4} \mathrm{In}_{12} \mathrm{Se}_{20}$. Chem.-A Eur. J. 2007, 13, 51-58. [CrossRef]

6. Hamza, M.F.; Hamad, N.A.; Hamad, D.M.; Khalafalla, M.S.; Abdel-Rahman, A.A.; Zeid, I.F.; Wei, Y.; Hessien, M.M.; Fouda, A.; Salem, W.M. Synthesis of ecofriendly biopolymer, alginate-chitosan composite to adsorb the heavy metals, $\mathrm{Cd}(\mathrm{II})$ and $\mathrm{Pb}$ (II) from contaminated effluents. Materials 2021, 14, 2189. [CrossRef]

7. Blokhin, A.A.; Murashkin, Y.V.; Mikhaylenko, M.A. Ion exchange treatment of cobalt acetate solutions to remove iron (III) impurity. Russ. J. Appl. Chem. 2021, 94, 116-121. [CrossRef]

8. Hunter, H.A.; Ling, F.T.; Peters, C.A. Coprecipitation of heavy metals in calcium carbonate from coal fly ash leachate. ACS EST Water 2021, 1, 339-345. [CrossRef]

9. Pettipher, G.L.; Mansell, R.; McKinnon, C.H.; Cousins, C.M. Rapid membrane filtration-epifluorescent technique for direct enumeration of bacteria in raw milk. Appl. Environ. Microb. 1980, 39, 423-429. [CrossRef]

10. Malara, A.; Fotia, A.; Paone, E.; Serrano, G. Electrospun nanofibers and electrochemical techniques for the detection of heavy metal ions. Materials 2021, 14, 3000. [CrossRef]

11. Saeki, D.; Yonamine, G.; Matsuyama, H. Effect of hydrophilic polymer modification of reverse osmosis membrane surfaces on organic adsorption and biofouling behavior. Colloid Surf. A 2021, 609, 125680. [CrossRef]

12. El-Halim, E.H.A.; El-Gayar, D.A.; Farag, H. Removal of copper ions from wastewater by ion exchange resin using pulsation technique. Mater. Sci. Forum. 2020, 1008, 191-201. [CrossRef]

13. Nilchi, A.; Atashi, H.; Javid, A.H.; Saberi, R. Preparations of PAN-based adsorbers for separation of cesium and cobalt from radioactive wastes. Appl. Radiat. Isot. 2007, 65, 482-487. [CrossRef] [PubMed]

14. Moradi, G.; Zinadini, S.; Rajabi, L.; Derakhshan, A.A. Removal of heavy metal ions using a new high performance nanofiltration membrane modified with curcumin boehmite nanoparticles. Chem. Eng. J. 2020, 390, 124546. [CrossRef]

15. Wang, C.; Luo, Y.; He, X.; Hong, D.; Wang, J.; Chen, F.; Chen, C.; Sun, B. Porous high-valence metal-organic framework featuring open coordination sites for effective water adsorption. Inorg. Chem. 2019, 58, 3058-3064. [CrossRef] [PubMed]

16. Li, W.; Liu, X.; Hu, Y.; Teng, F.; Hu, Y. Potassium isotopic fractionation during clay adsorption. Geochim. Cosmochim. Acta 2021, 304, 160-177. [CrossRef]

17. Jiang, B.; Jiang, N.; Chang, Y. Synthesis of highly active $\mathrm{Cu}(\mathrm{I})-\mathrm{Y}(\mathrm{III})-\mathrm{Y}$ zeolite and its selective adsorption desulfurization performance in presence of xylene isomers. Pet. Sci. 2021, 18, 295-306. [CrossRef]

18. Miao, Y.; Peng, W.; Cao, Y.; Chang, L.; Fan, G.; Yu, F. Facile preparation of sulfhydryl modified montmorillonite nanosheets hydrogel and its enhancement for $\mathrm{Pb}(\mathrm{II})$ adsorption. Chemosphere 2021, 280, 130727. [CrossRef]

19. Le, L.H.T.; Nguyen, S.A.; Nguyen, T.D.; Le, V.C.T.; Cao, H.V.; Nguyen, N.B.; Le, T.P.T. Prussian blue analogues of $\mathrm{A}_{2}\left[\mathrm{Fe}(\mathrm{CN})_{6}\right](\mathrm{A}$ $\mathrm{Cu}^{2+}, \mathrm{Co}^{2+}$, and $\mathrm{Ni}^{2+}$ ) and their composition-dependent sorption performances towards $\mathrm{Cs}^{+}, \mathrm{Sr}^{2+}$, and $\mathrm{Co}^{2+}$. J. Nanomater. 2021, 2021, 5533620. [CrossRef]

20. Chen, J.H.; Liu, P.S.; Cheng, W. PBA-loaded albite-base ceramic foam in application to adsorb harmful ions of Cd, Cs and As(V) in water. Multidiscip. Model. Mater. Struct. 2019, 15, 659-672. [CrossRef]

21. Hu, C.-W.; Kawamoto, T.; Tanaka, H.; Takahashi, A.; Lee, K.-M.; Kao, S.-Y.; Liao, Y.-C.; Ho, K.-C. Water processable Prussian blue-polyaniline: Polystyrene sulfonate nanocomposite (PB-PANI:PSS) for multi-color electrochromic applications. J. Mater. Chem. C 2016, 4, 10293-10300. [CrossRef]

22. Moosavian, M.A.; Moazezi, N. Removal of cadmium and zinc ions from industrial wastewater using nanocomposites of PANI/ZnO and PANI/CoHCF: A comparative study. Desalination Water Treat. 2016, 57, 20817-20836. [CrossRef]

23. Ishizaki, M.; Akiba, S.; Ohtani, A.; Hoshi, Y.; Ono, K.; Matsuba, M.; Togashi, T.; Kananizuka, K.; Sakamoto, M.; Takahashi, A Proton-exchange mechanism of specific $\mathrm{Cs}^{+}$adsorption via lattice defect sites of Prussian blue filled with coordination and crystallization water molecules. Dalton Trans. 2013, 42, 16049-16055. [CrossRef] [PubMed]

24. Ohara, E.; Soejima, T.; Ito, S. Removal of low concentration Cs(I) from water using Prussian blue. Inorg. Chim. Acta 2021, 514, 120029. [CrossRef]

25. Fang, Q.; Li, G.; Lin, H.; Liu, F. Solar-driven organic solvents purification enabled by robust cubic Prussian blue. J. Mater. Chem. A 2019, 7, 8960-8966. [CrossRef]

26. Bilal, M.; Shah, J.A.; Ashfaq, T.; Gardazi, S.; Tahir, A.A.; Pervez, A.; Haroon, H.; Mahmood, Q. Waste biomass adsorbents for copper removal from industrial wastewater-a review. J. Hazard. Mater. 2013, 263, 322-333. [CrossRef]

27. Hou, X.; Sun, L.; Hu, Y.; An, X.; Qian, X. De-doped polyaniline as a mediating layer promoting in-situ growth of metal-organic frameworks on cellulose fiber and enhancing adsorptive-photocatalytic removal of ciprofloxacin. Polymers 2021, $13,3298$. [CrossRef]

28. Chen, Y.; Li, S.; Pei, X.; Zhou, J.; Feng, X.; Zhang, S.; Cheng, Y.; Li, H.; Han, R.; Wang, B. A solvent-free hot-pressing method for preparing metal-organic-framework coatings. Angew. Chem. Int. Ed. 2016, 55, 3419-3423. [CrossRef]

29. Silva Pinto, M.D.; Sierra-Avila, C.A.; Hinestroza, J.P. In situ synthesis of a Cu-BTC metal-organic framework (MOF 199) onto cellulosic fibrous substrates: Cotton. Cellulose 2012, 19, 1771-1779. [CrossRef] 
30. Duan, C.; Meng, J.; Wang, X.; Meng, X.; Sun, X.; Xu, Y.; Zhao, W.; Ni, Y. Synthesis of novel cellulose-based antibacterial composites of Ag nanoparticles@metal-organic frameworks@carboxymethylated fibers. Carbohydr. Polym. 2018, 193, 82-88. [CrossRef]

31. Zhao, J.; Losego, M.D.; Lemaire, P.C.; Williams, P.S.; Gong, B.; Atanasov, S.E.; Blevins, T.M.; Oldham, C.J.; Walls, H.J.; Shepherd, S.D.; et al. Highly adsorptive, MOF-functionalized nonwoven fiber mats for hazardous gas capture enabled by atomic layer deposition. Adv. Mater. Interfaces 2014, 1, 1400040. [CrossRef]

32. Bao, T.; Su, Y.; Zhang, N.; Gao, Y.; Wang, S. Hydrophilic carboxyl cotton for in situ growth of UiO-66 and its application as adsorbents. Ind. Eng. Chem. Res. 2019, 58, 20331-20339. [CrossRef]

33. Abdelhameed, R.M.; Kamel, O.M.H.M.; Amr, A.; Rocha, J.; Silva, A.M.S. Antimosquito activity of a titanium-organic framework supported on fabrics. ACS Appl. Mater. Inter. 2017, 9, 22112-22120. [CrossRef] [PubMed]

34. Shen, C.; Mao, Z.; Xu, H.; Zhang, L.; Zhong, Y.; Wang, B.; Feng, X.; Tao, C.; Sui, X. Catalytic MOF-loaded cellulose sponge for rapid degradation of chemical warfare agents simulant. Carbohydr. Polym. 2019, 213, 184-191. [CrossRef] [PubMed]

35. Au-Duong, A.N.; Lee, C.K. Flexible metal-organic framework-bacterial cellulose nanocomposite for iodine capture. Cryst. Growth Des. 2018, 18, 356-363. [CrossRef]

36. Zhang, Y.; Tu, L.; Zeng, Q.; Kong, X. Effect of protein molecules on the photoluminescence properties and stability of water-soluble CdSe/ZnS core-shell quantum dots. Chin. Sci. Bull. 2013, 58, 2616-2621. [CrossRef]

37. Mao, H.; Wu, X.; Qian, X.; An, X. Conductivity and flame retardancy of polyaniline-deposited functional cellulosic paper doped with organic sulfonic acids. Cellulose 2014, 21, 697-704. [CrossRef]

38. Zhou, Y.; Ding, C.; Qian, X.; An, X. Further improvement of flame retardancy of polyaniline-deposited paper composite through using phytic acid as dopant or co-dopant. Carbohydr. Polym. 2015, 115, 670-676. [CrossRef]

39. Chang, Z.; An, X.; Qian, X. High mass loading polyaniline layer anchored cellulose fibers: Enhanced interface junction for high conductivity and flame retardancy. Carbohydr. Polym. 2020, 230, 115660. [CrossRef]

40. Rafiqi, F.A.; Majid, K. Removal of copper from aqueous solution using polyaniline and polyaniline/ferricyanide compo-site. J. Environ. Chem. Eng. 2015, 3, 2492-2501. [CrossRef]

41. Lei, H.; Pan, N.; Wang, X.; Zou, H. Facile synthesis of phytic acid impregnated polyaniline for enhanced U(VI) adsorption. J. Chem. Eng. Data 2018, 63, 3989-3997. [CrossRef]

42. Kim, H.J.; Im, S.; Kim, J.C.; Hong, W.G.; Shin, K.; Jeong, H.Y.; Hong, Y.J. Phytic acid doped polyaniline nanofibers for enhanced aqueous copper(II) adsorption capability. ACS Sustain. Chem. Eng. 2017, 5, 6654-6664. [CrossRef]

43. Ali, M.B.; Wang, F.; Boukherroub, R.; Lei, W.; Xia, M. Phytic acid-doped polyaniline nanofibers-clay mineral for efficient adsorption of copper (II) ions. J. Colloid Interf. Sci. 2019, 553, 688-698.

44. Moharram, M.A.; Mahmoud, O.M. X-ray diffraction methods in the study of the effect of microwave heating on the transformation of cellulose I into cellulose II during mercerization. J. Appl. Polym. Sci. 2010, 105, 2978-2983. [CrossRef]

45. Xu, L.; Sun, Y.; Han, B.; Su, C. Preparation of polyaniline/FeFe $(\mathrm{CN})_{6}$ composite and its electrochemical performance as cathode material of lithium ion battery. Nano 2020, 15, 2050107. [CrossRef]

46. Srivastava, N.; Shripathi, T.; Srivastava, P.C. Core level X-ray photoelectron spectroscopy study of exchange coupled Fe/NiO bilayer interfaced with $\mathrm{Si}$ substrate (Fe/NiO-nSi structure). J. Electron Spectrosc. Relat. Phenom. 2013, 191, 20-26. [CrossRef]

47. Chen, H.Y.; Chen, L.; Lin, J.; Tan, K.L.; Li, J. Copper sites in copper-exchanged ZSM-5 for CO activation and methanol synthesis: XPS and FTIR studies. Inorg. Chem. 1997, 36, 1417-1423. [CrossRef]

48. Qusti, A.H. Removal of chromium(VI) from aqueous solution using manganese oxide nanofibers. J. Ind. Eng. Chem. 2014, 20, 3394-3399. [CrossRef]

49. Ho, Y.S.; McKay, G. Pseudo-second order model for sorption processes. Process Biochem. 1999, 34, 451-465. [CrossRef]

50. Long, Q.; Kang, B.; Dai, Y.D.; Li, J. Study of adsorption of copper ion in radioactive wastewater by zinc ferrocyanide. Int. Mater. Rev. 2014, 28, 95-98.

51. Gregg, S.J.; Sing, K.S.W. Adsorption Surface Area and Porosity; Academic Press: London, UK, 1982.

52. Wang, N.; Chen, J.; Wang, J.; Feng, J.; Yan, W. Removal of methylene blue by polyaniline/TiO 2 hydrate: Adsorption kinetic, isotherm and mechanism studies. Powder Technol. 2019, 347, 93-102. [CrossRef]

53. Febrianto, J.; Kosasiha, A.N.; Sunarso, J.; Ju, Y.H.; Indraswati, N.; Ismadji, S. Equilibrium and kinetic studies in adsorption of heavy metals using biosorbent: A summary of recent studies. J. Hazard. Mater. 2009, 162, 616-645. [CrossRef] [PubMed]

54. Qu, R.; Wang, M.; Song, R.; Sun, C.; Zhang, Y.; Sun, X.; Ji, C.; Wang, C.; Yin, P. Adsorption kinetics and isotherms of Ag(I) and $\mathrm{Hg}$ (II) onto silica gel with functional groups of hydroxyl- or amino-terminated polyamines. J. Chem. Eng. Data 2011, 56, 1982-1990. [CrossRef] 